Annales Geophysicae (2003) 21: 559-576 (C) European Geosciences Union 2003

\title{
High-latitude observations of impulse-driven ULF pulsations in the ionosphere and on the ground
}

\author{
F. W. Menk ${ }^{1,3}$, T. K. Yeoman ${ }^{2}$, D. M. Wright ${ }^{2}$, M. Lester ${ }^{2}$, and F. Honary ${ }^{4}$ \\ ${ }^{1}$ School of Mathematical and Physical Science, the University of Newcastle, Callaghan, NSW 2308, Australia \\ ${ }^{2}$ Department of Physics and Astronomy, University of Leicester, University Road, Leicester, LE1 7RH, UK \\ ${ }^{3}$ Also at: Cooperative Research Centre for Satellite Systems, Canberra, ACT, Australia \\ ${ }^{4}$ Department of Communications Systems, Lancaster University, Lancaster, LA1 4YR, UK
}

Received: 27 September 2001 - Revised: 3 July 2002 - Accepted: 11 July 2002

\begin{abstract}
We report the simultaneous observation of 1.6$1.7 \mathrm{mHz}$ pulsations in the ionospheric F-region with the CUTLASS bistatic HF radar and an HF Doppler sounder, on the ground with the IMAGE and SAMNET magnetometer arrays, and in the upstream solar wind. CUTLASS was at the time being operated in a special mode optimized for high resolution studies of ULF waves. A novel use is made of the ground returns to detect the ionospheric signature of ULF waves. The pulsations were initiated by a strong, sharp decrease in solar wind dynamic pressure near 09:28 UT on 23 February 1996, and persisted for some hours. They were observed with the magnetometers over $20^{\circ}$ in latitude, coupling to a field line resonance near $72^{\circ}$ magnetic latitude. The magnetic pulsations had azimuthal $m$ numbers $\sim-2$, consistent with propagation away from the noon sector. The radars show transient high velocity flows in the cusp and auroral zones, poleward of the field line resonance, and small amplitude $1.6-1.7 \mathrm{mHz}$ F-region oscillations across widely spaced regions at lower latitudes. The latter were detected in the radar ground scatter returns and also with the vertical incidence Doppler sounder. Their amplitude is of the order of $\pm 10 \mathrm{~m} \mathrm{~s}^{-1}$. A similar perturbation frequency was present in the solar wind pressure recorded by the WIND spacecraft. The initial solar wind pressure decrease was also associated with a decrease in cosmic noise absorption on an imaging riometer near $66^{\circ}$ magnetic latitude. The observations suggest that perturbations in the solar wind pressure or IMF result in fast compressional mode waves that propagate through the magnetosphere and drive forced and resonant oscillations of geomagnetic field lines. The compressional wave field may also stimulate ionospheric perturbations. The observations demonstrate that HF radar ground scatter may contain important information on small-amplitude features, extending the scope and capability of these radars to track features in the ionosphere.
\end{abstract}

Key words. Ionosphere (Ionosphere-magnetosphere inter-

Correspondence to: F. W. Menk (fred.menk@ physics.org or Fred.Menk@newcastle.edu.au) actions; ionospheric disturbances) - Magnetospheric physics (MHD waves and instabilities)

\section{Introduction}

This paper reports new observations of the ionospheric and magnetic signatures of solar wind pressure perturbations. In particular, we describe the novel use of HF radar ground scatter to detect ionospheric pulsations.

Geomagnetic activity is driven by energy and mass transfer from the solar wind, and the outermost sunward field lines map most directly to the particle and wave entry regions. The injected particles may give rise to features of dayside auroras (Lui and Sibeck, 1991), while the waves may propagate large distances through the magnetosphere and couple to field line resonances (e.g. Warnecke et al., 1990).

Transient features are often observed in high-latitude magnetometer and ionospheric data, although their interpretation may be controversial. Possible generation mechanisms include radial displacements of the magnetopause due to perturbations in the solar wind dynamic pressure (Farrugia et al., 1989; Sibeck, 1990) or impulsive magnetic reconnection and plasma transfer events at the magnetopause (Lemaire, 1977; Russell and Elphic, 1979; Saunders et al., 1984). KelvinHelmholtz surface waves driven by the velocity shear at the magnetopause may also produce similar signatures in ground magnetometer records (Pu and Kivelson, 1983). It is necessary to carefully study specific events in order to distinguish the causative mechanism. An important aspect of this is the intercalibration of signatures from different instruments.

This paper presents observations of ULF pulsations recorded in the high-latitude ionosphere with the CUTLASS bistatic HF radar and a Doppler sounder, and on the ground with the IMAGE and SAMNET magnetometer arrays, on 23 February 1996. The pulsations were stimulated by solar wind perturbations and were recorded across a wide region on the ground with the same frequency as in the solar wind pressure and IMF. The ionospheric pulsations were observed 
in the CUTLASS ground scatter return. This raises the possibility of using ground scatter data to extend the capability and resolution of HF radars. Sibeck (1990) presented a detailed description of the magnetospheric response to a solar wind pressure pulse, and our observations support and extend those predictions.

\section{Instrumentation}

\subsection{Ionospheric observations}

In this study we examined the ionospheric F-region near Troms $\emptyset$, Norway, using a number of techniques, the main one being the CUTLASS bistatic HF coherent radar. CUTLASS comprises stations at Pykkvibaer in Iceland and Hankasalmi in Finland, and is a component of the international SuperDARN HF radar network (Greenwald et al., 1995). In standard operating mode these radars sweep over a $52^{\circ}$ azimuth sector using 16 evenly spaced beams. This is represented by the fan-shaped regions in Fig. 1. Each beam is gated into up to 75 range bins with spatial resolution of typically $45 \mathrm{~km}$ by $100 \mathrm{~km}$ at midrange, giving a total field of view of the order of $3 \times 10^{6} \mathrm{~km}^{2}$. In standard mode, the integration time for each beam position is $7 \mathrm{~s}$, and the cycle time is $2.0 \mathrm{~min}$.

The operation of HF radars was described by Greenwald et al. (1985). In normal operation these radars detect echoes that are coherently backscattered from $\sim 10$-m scale field-aligned ionospheric plasma density irregularities, when the radar beam direction is close to orthogonal to the $\boldsymbol{B}$ field. These irregularities are produced in the high-latitude F-region by plasma drifts and density gradients (e.g. Fejer and Kelley, 1980; Tsunoda, 1988) and drift with the ambient plasma motion (Villain et al., 1985). In each beam the radars measure the line-of-sight Doppler velocity, the backscattered power, and the spectral width of the echo from these structures.

The CUTLASS Iceland East radar looks across the magnetic meridian and thus is well suited to identifying features moving azimuthally. The Finland radar looks toward the magnetic pole and accordingly is better suited for examining equatorward or poleward moving features. Further details on CUTLASS are available at http://ion.le.ac.uk/cutlass/cutlass. html.

The observations reported here were obtained when CUTLASS was operating in a non-standard scan mode, optimised for high resolution studies of a specific target region. In this mode three adjacent beams are scanned, with the central beamed scanned again between each set. The Finland radar thus scanned beams $6,7,6,5,6,7,6, \ldots$, and similarly the Iceland East radar scans were centered on beam 14 . These beams were sampled each $7 \mathrm{~s}$ and the first range gate was set at a distance of $180 \mathrm{~km}$. The radio frequency was in the range 9900-10 $000 \mathrm{MHz}$, appropriate for F-region reflections. These central beams are represented in Fig. 1 by broken lines, and intersect in the F-region just east of Troms $\emptyset$.
An important feature of radars such as CUTLASS is the measurement of the elevation angle of the backscatter returns. This is achieved using an interferometric technique and can assist in discriminating the direction of ground scatter and the altitude of irregularity structures (Milan et al., 1997a, b).

We will also present results from a near-vertical incidence ionospheric Doppler sounder experiment that was located near Troms $\varnothing$. Called DOPE (DOppler Pulsation Experiment), this monitored the amplitude and Doppler shift of the ordinary (O-mode) and extraordinary (X-mode) reflections from the F-region at a frequency of $4.45 \mathrm{MHz}$ with a time resolution of $12.8 \mathrm{~s}$. The experiment was described in detail by Wright et al. (1997), where typical results were also presented. Whereas the two CUTLASS radars can measure the horizontal convection velocity components, DOPE provides a measurement of vertical motions in more or less the same part of the F-region.

General information on the ionosphere in this region is available from the Troms $\emptyset$ dynasonde operated by EISCAT. The dynasonde is a digital frequency-agile HF sounder that can operate in a number of modes. During the interval of interest here, digital ionograms resolving the $\mathrm{O}$ - and $\mathrm{X}$-modes were available from the dynasonde every $3 \mathrm{~min}$. Further details on the EISCAT dynasonde can be found in Sedgemore et al. (1996) and at http://www.eiscat.uit.no/dynasond.html.

Finally, information on the magnitude and structure of Dregion absorption can be obtained from the IRIS (Imaging Riometer for Ionospheric Studies) experiment operated at Kilpisjärvi (KIL), Finland, by the University of Lancaster. IRIS examines ionospheric absorption of incoming galactic radio noise at a frequency of $38.2 \mathrm{MHz}$ with 49 beams and a sampling time of $1 \mathrm{~s}$. Resolution of the riometer is $0.05 \mathrm{~dB}$. The experiment was described in detail by Detrick and Rosenberg (1990) and Browne et al. (1995); further details appear at http://www.dcs.lancs.ac.uk/iono/iris/. Figure 1 shows that KIL is also very near the region where the CUTLASS beams intersect.

\subsection{Ground magnetometer arrays}

Magnetometer data were obtained from the IMAGE and SAMNET arrays that span Scandinavia and Svalbard. Station locations are represented by triangles and squares, respectively, in Fig. 1. The IMAGE (International Monitor for Auroral Geomagnetic Effects) array was described by Lühr (1994) and Lühr et al. (1998) and comprises fluxgate magnetometers sampling the geographic $X, Y$ and $Z$ components of the geomagnetic field each $10 \mathrm{~s}$ with a resolution of $0.1-1 \mathrm{nT}$. Data were rotated into the geomagnetic $H, D$ and $Z$ reference frame for use here. Further details of IMAGE, including station coordinates, are available at http://www.geo.fmi.fi/image/. SAMNET (UK Sub-Auroral Magnetometer NETwork) consists of fluxgate magnetometers that, during the interval considered here, sampled the geomagnetic $H, D$ and $Z$ components each $5 \mathrm{~s}$ with a res- 

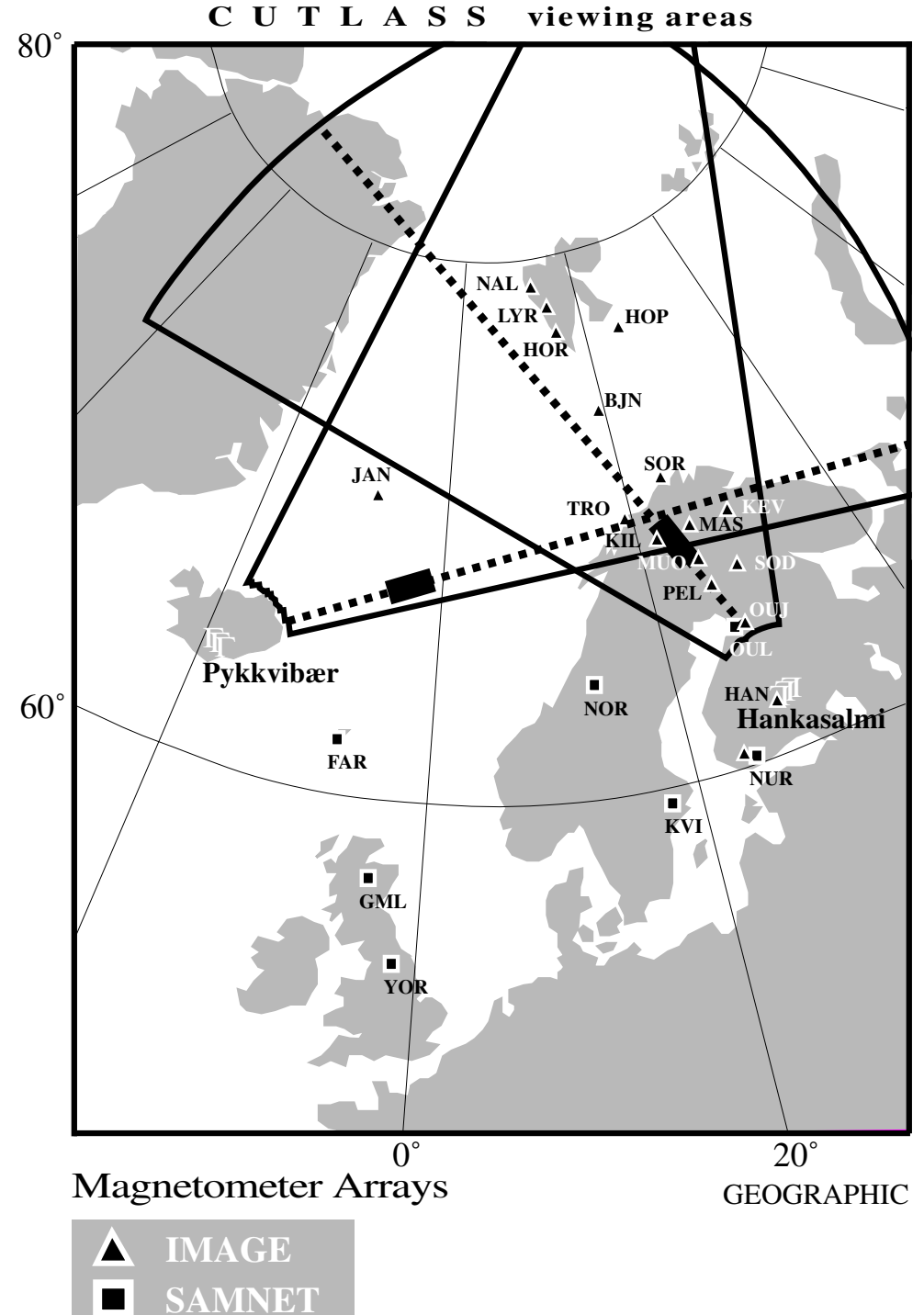

Fig. 1. Map in geographic coordinates showing CUTLASS beams and ranges of interest, and IMAGE and SAMNET magnetometer locations. Shaded boxes depict ionospheric reflection regions for ground scatter recorded by beam 6 of the Finland radar and beam 14 of the Iceland East radar. The DOPE Doppler sounder was located just east of Troms $\varnothing$, and the IRIS imaging riometer at KIL. olution of $0.25 \mathrm{nT}$. Further details appear in Yeoman et al. (1990a) and at http://samsun.york.ac.uk/samnet_home.html.

\subsection{Solar wind and DMSP data}

Solar wind data presented in this paper are from the WIND spacecraft, which at the time of interest was located upstream near $\operatorname{GSE}(x, y, z)=(172.5,-5.6,11.23) R_{E}$. We used solar wind and magnetic field data from the SWE (Solar Wind Experiment) and MFI (Magnetic Fields Investigation) instruments, respectively. Further information on these experiments is given in Ogilvie et al. (1995) and Lepping et al. (1995), and at http://www-istp.gsfc.nasa.gov/istp/wind/ wind.html.

General information on magnetospheric topology was obtained by reference to ion and electron flux data from the DMSP F12 spacecraft. This is one of a series of spacecraft in an approximately $830 \mathrm{~km}$ altitude Sun-synchronous, 101-min period polar orbit. Spectra of low energy ion and electron fluxes at high-latitudes are produced by the SSJ/4 electrostatic analyzer instruments, described by Hardy et al. (1985). Further details on DMSP may be obtained from http://sd-www.jhuapl.edu/Aurora/. The use of DMSP particle spectra to infer the locations of the magnetospheric boundaries has been discussed by Newell and Meng (1988, 1992) and Newell et al. $(1989,1991)$.

\section{Observations}

\subsection{Solar wind}

The observations to be discussed are from 23 February 1996, when Pc5 magnetic pulsations were recorded for several hours across the IMAGE and SAMNET magnetometer arrays, with corresponding Doppler shift oscillations occurring in the CUTLASS and DOPE records. $K_{p}$ during this time 

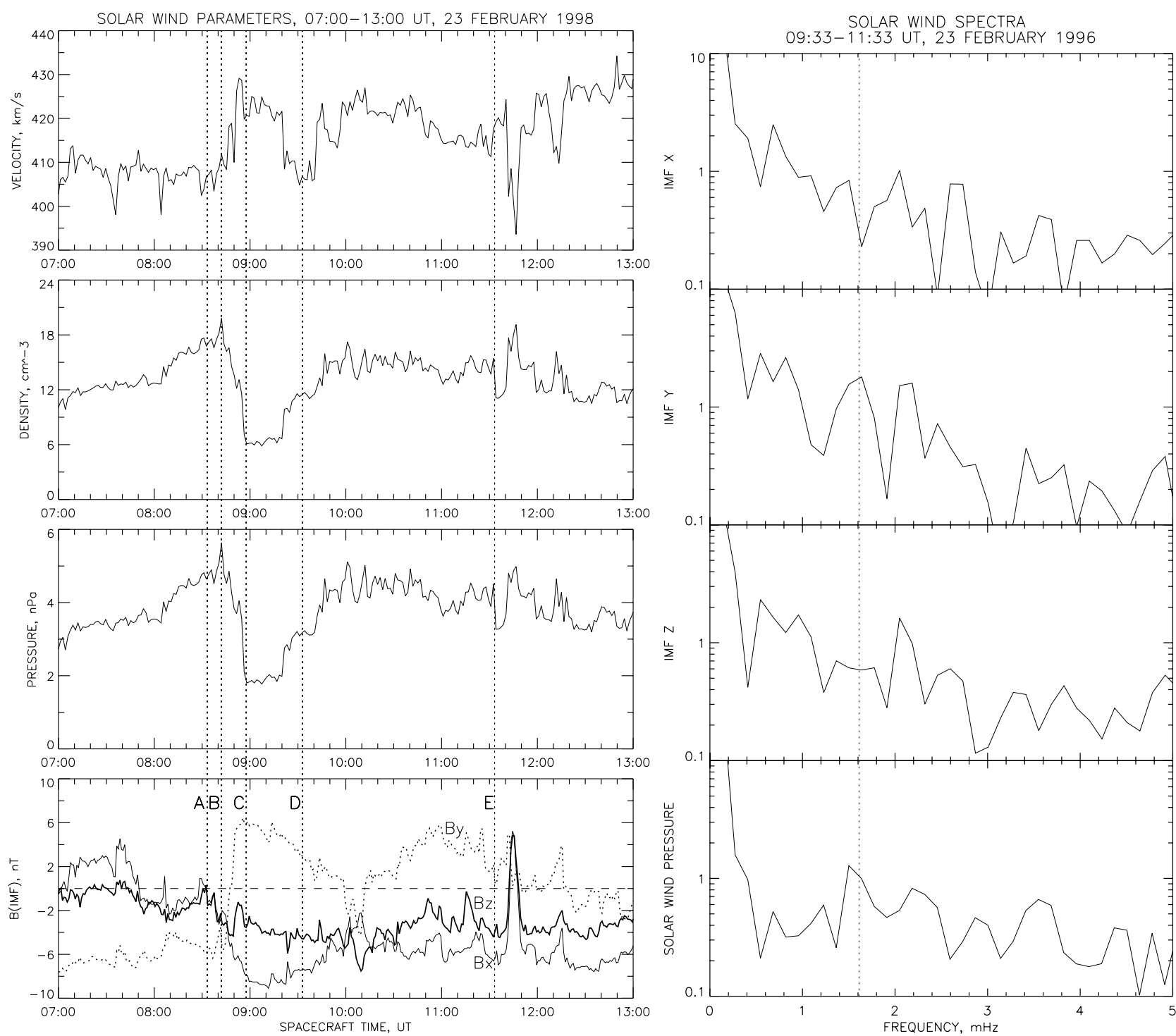

Fig. 2. (a, left) WIND solar wind plasma and magnetic field data, 07:00-13:00 UT, 23 February 1996. Top three panels show the solar wind speed, then ion density, dynamic pressure, and magnetic field, all in GSM coordinates. For the bottom panel the thin solid line represents the $B_{x}$ component, the dotted line the $B_{y}$ component, and the thick solid line the $B_{z}$ component. Vertical dotted lines denote times when $B_{z}$ turns negative (labelled "A"), when solar wind pressure begins to drop ("B") and reaches minimum ("C"), and the interval of oscillations considered in detail ("D" to "E").

(b, right) Power spectrum of three components of the IMF and solar wind dynamic pressure, 09:33-11:33 UT (spacecraft time; 10:2012:20 UT on the ground), 23 February 1996. Resolution is approximately $0.14 \mathrm{mHz}$ and time series are unfiltered. Vertical dotted line indicates frequency of $1.6 \mathrm{mHz}$ seen in ionospheric and ground magnetometer data.

was in the range $2+$ to $3+$, but had been low over the previous few days $\left(\Sigma K_{p}=8.7,14\right.$ and 18 on 21,22 and 23 February, respectively).

WIND observations of the solar wind plasma and magnetic field conditions from 07:00 UT to 13:00 UT on 23 February are presented in Fig. 2a. The top panel shows solar wind velocity, with density and pressure in the next panels. The bottom panel presents the corresponding WIND IMF data in GSM coordinates, where the thick solid line represents the $B_{z}$ component, the dotted line represents the $B_{y}$ component, and the thin solid line represents the $B_{x}$ component.

The solar wind speed was generally in the range $V=405-$ $430 \mathrm{~km} \mathrm{~s}^{-1}$ throughout the interval shown. This includes a sharp increase from $\sim 410$ to $\sim 430 \mathrm{~km} \mathrm{~s}^{-1}$ around 08:50 UT and a subsequent decrease at $\sim 09: 22 \mathrm{UT}$.

There are several features of interest in the solar wind density, pressure and IMF plots. These are identified by vertical dotted lines labelled "A" to "E". First, there is a small southward turning of $B_{z}$ at 08:32 UT, labelled "A", after which 
the $B_{x}$ and $B_{z}$ components are strongly negative. This is followed by a sharp decrease in ion density, from $n \sim 20 \mathrm{~cm}^{-3}$ at 08:41 UT ("B") to $6 \mathrm{~cm}^{-3}$ at 08:57 UT ("C"). This caused a decrease in solar wind pressure, $n V^{2}$, by a factor of about 3 between these times. The pressure decrease commencing at 08:41 UT ("B") also initiates a strong positive transition of $B_{y}$, which later goes briefly negative again between 09:59 UT and 10:12 UT.

We have calculated the propagation lag from WIND to the magnetopause and ionosphere using the formula given by Lockwood et al. (1989) and assuming an Alfvén wave transit time through the magnetosphere to the ionosphere of $2 \mathrm{~min}$. The time lag from WIND to the ionosphere varies from nearly $50 \mathrm{~min}$ at "A" and "B" to $47 \mathrm{~min}$ for the later events. For simplicity, we henceforth assume a fixed 47-min lag from the satellite to the ionosphere. This will not affect the discussion of the sequence of observations.

Accordingly, the negative pressure pulse at 08:41 UT ("B" in Fig. 2a) should reach the ionosphere at $\sim 09: 28 \mathrm{UT}$, and the maximum depth of the pressure pulse ("C") occurs at the ionosphere at 09:44 UT. The solar wind pressure commences recovery to near its original value at $\sim 09: 20$ UT (at WIND).

Periodic solar wind pressure fluctuations with amplitude up to $25 \%$ of the total amplitude occurred for some hours after the pressure decrease. These commenced around 09:33 UT at WIND and 10:20 UT at the ionosphere ("D"), and ended at WIND around 11:33 UT ("E") and 12:20 UT at the ionosphere. Figure $2 \mathrm{~b}$ shows power spectra of the three components of the IMF and the solar wind dynamic pressure measured by WIND between 09:33 UT and 11:33 UT ( 10:20-12:20 UT at the ionosphere). The spectra were computed using a single FFT, weighted by a Hanning window and with no detrending or filtering. Frequency resolution of the spectra is approximately $0.14 \mathrm{mHz}$. The spectra show a peak in solar wind pressure variations with a frequency near $1.5-1.7 \mathrm{mHz}$ (period 10-11 min), which is double the power of the adjacent peaks. The IMF $B_{y}$ component shows peaks near 1.6 and $2.1 \mathrm{mHz}$, the $B_{z}$ component has a peak near $2.1 \mathrm{mHz}$ only, and no clear peak is present in the $B_{x}$ spectrum. Note that there do not appear to be any steplike transients in the solar wind pressure or in the $B_{x}$ and $B_{z}$ components during this interval (see Fig. 2a). However, there is a significant transient variation in $B_{y}$, as mentioned earlier.

According to a formula given by Farrugia et al. (1989), the negative solar wind pressure pulse would have resulted in sunward motion of the magnetopause of $\sim 1.9 R_{E}$, and the subsequent fluctuations would have caused motions of the order of $0.2-0.4 R_{E}$.

\subsection{Cutlass radar}

HF radar data are typically presented in the form of wholeday range-time parameter plots for a particular beam. $\mathrm{Pa}$ rameters of interest are the power, the line-of-sight velocity, the elevation angle, and the spectral width (in $\mathrm{m} \mathrm{s}^{-1}$ ) of the returned signal. Backscatter regions of small velocity and spectral width are normally considered to indicate ground scatter and their plotting is usually suppressed. In the following plots we have not suppressed this low velocity, low spectral width information.

Figure 3 presents combined range-time-velocity plots for beam 6 from the Finland radar and beam 14 from the Iceland East radar, from 09:00 to 13:00 UT on 23 February. Panels (a) and (c) present Doppler velocity data that has been identified as coming from ionospheric scatter, while panels (b) and (d) present Doppler velocity data that has been identified as coming from ground scatter. Milan et al. (1997a) have discussed the distinction between ionospheric and ground scatter in HF radar returns. Figure 3 shows many complicated features. Milan et al. (1998) presented plots of the Finland beam 5 power, velocity and elevation angle for this day, and provided a detailed discussion of the features observed.

We consider first the Finland velocity plot shown in Fig. 3a. There is a prominent zone of periodic high velocity poleward moving features (negative velocity = away from radar $=$ red $)$, commencing near 09:20 UT between 76-80 magnetic latitude (range gates 45-50) and moving to 72 $76^{\circ}$ latitude (gates 40-45) by 13:00 UT. The corresponding power level plot (not presented here but see Milan et al., 1998) shows that this zone is associated with high backscattered power. In radar data the cusp footprint is associated with a complex Doppler spectrum and broad spectral width (Baker et al., 1995). The spectral width plot (not given) shows irregular and high spectral widths $\left(450 \mathrm{~m} \mathrm{~s}^{-1}\right)$ from $76-80^{\circ}$ latitude at 09:30 UT. Finland beam 6 points $18^{\circ}$ west of geographic north and the high velocity, high spectral width zone lies magnetically poleward and somewhat west of Svalbard. We interpret this zone as the signature of the dayside auroral oval, and henceforth refer to radar returns from this region as ionospheric scatter. The negative, pulsed velocity structures throughout the interval represent antisunward flow, and are characterised by broad radar spectral widths. As such, they are typical of the radar cusp scatter under IMF $B_{z}$ south conditions (Pinnock et al., 1993, 1995; Provan et al., 1998; Neudegg et al., 1999).

The DMSP F13 spacecraft passed over the arctic region northwest of Svalbard around 08:47 UT on this day. The observed particle energies and fluxes indicate that the cusp and open/closed field line boundary were located $\sim 75^{\circ}$ magnetic latitude. This lends confidence to our identification of the high velocity region as cusp/dayside auroral oval and agrees with the magnetometer observations presented later.

The solar wind pressure decrease arriving at the ionosphere around 09:30 UT appeared to initiate or enhance periodic antisunward flow bursts in the cusp ionosphere that lasted about two hours. The period of the features here is of the order of $10 \mathrm{~min}$. The equatorward movement of the low-latitude boundary of this flow zone at $\sim 10: 45$ UT is indicative of an expanding polar cap resulting from dayside reconnection under IMF $B_{z}$ south conditions.

We now examine the low velocity region in the Finland radar data, shown in Fig. 3b. This extends from $66^{\circ}$ to $>70^{\circ}$ 


\title{
SUPERDARN PARAMETER PLOT 23 Feb 1996
}

\author{
Finland and Iceland East: vel
}

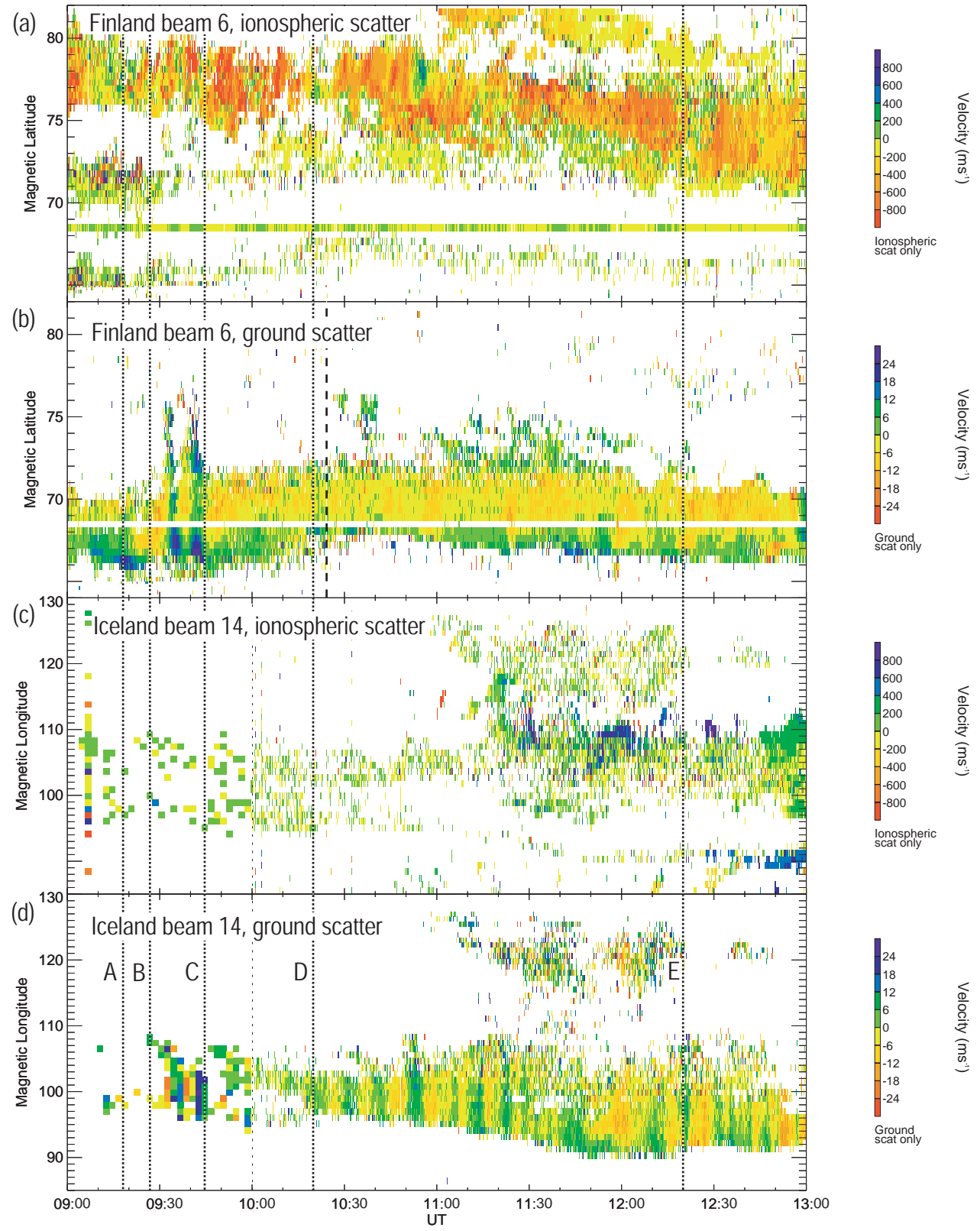

Fig. 3. Range-time-velocity plot for Finland beam 6 ionospheric scatter (top panel, (a) and ground scatter (b), and Iceland East beam 14 ionospheric scatter (c) and ground scatter (d), over 09:00-13:00 UT on 23 February 1996. Vertical dotted lines indicate approximate arrival times at the ionosphere of events labelled "A" to "E" in Fig. 2. Finland ground scatter in (b) before 10:24 UT, indicated by the vertical dashed line, is from behind the radar.

in magnetic latitude (range $\sim 1000-1500 \mathrm{~km}$ ). Figure 1 of Milan et al. (1998) shows that this region is characterised by high backscattered power $(40 \mathrm{~dB})$ and high elevation angles. Spectral widths are low $\left(<100 \mathrm{~m} \mathrm{~s}^{-1}\right)$. We denote this as ground scatter. Milan et al. (1998) have provided a detailed discussion on the interpretation of the elevation angle data and the location of ground scatter regions in front of and behind the radar on this day.

Immediately obvious in the Finland ground scatter in Fig. $3 \mathrm{~b}$ are patches of alternating velocity features extending up to $10^{\circ}$ in latitude, commencing with two prominent bands at $\sim 09: 30$ UT and 0936 UT. These follow the main so- 


\section{SUPERDARN PARAMETER PLOT CUTLASS Finland and Iceland East (vel) and DOPE}

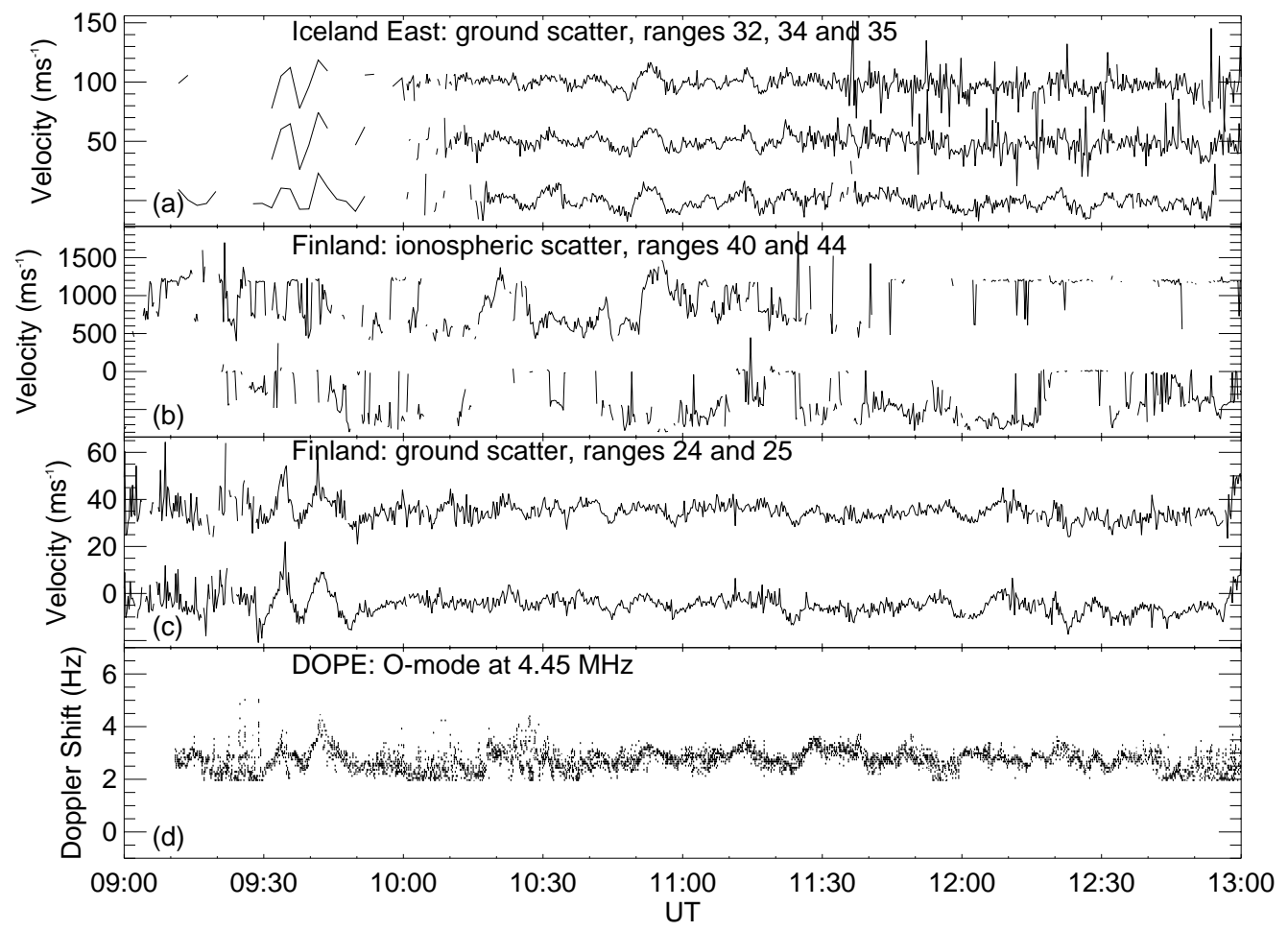

Fig. 4. Stacked velocity-time plot of CUTLASS and DOPE Doppler oscillations, 09:00-13:00 UT, 23 February 1996. The same CUTLASS beams are shown as in Fig. 3. The panels show, from top to bottom, Iceland East ground scatter, Finland ionospheric scatter, Finland ground scatter, and HF Doppler O-mode.

lar wind pressure decrease labelled "B" in Figs. 2a and 3. Alternating features due to velocity oscillations of amplitude $\pm 20 \mathrm{~m} \mathrm{~s}^{-1}$ or less, with period of $\sim 10 \mathrm{~min}$, are present for at least $3 \mathrm{~h}$, and have a very similar shape over $4-8$ range gates, i.e. over $180-360 \mathrm{~km}$ in latitude. We emphasise that these are ground backscatter features, not returns from field-aligned irregularity structures in the usual sense.

Now consider the Iceland East range-time-velocity plots, shown in Figs. $3 \mathrm{c}$ and d. The transition at 10:00 UT corresponds to the radar switching into the special high resolution mode. Of interest is the zone of low velocity bands in the bottom panel (d), commencing around 09:30 UT and visible during the entire plot interval. The bands extend over about 10 range gates $(\sim 450 \mathrm{~km})$ and are associated with high power levels, very low spectral widths, high elevation angles $\left(25-30^{\circ}\right)$, and line-of-sight velocities of the order of \pm 10 $20 \mathrm{~m} \mathrm{~s}^{-1}$. Detailed plots appear in Menk et al. (2001). The bands are due to velocity oscillations that were essentially simultaneous across the field of view and exhibited a 10-min periodicity. The zone of velocity structures gradually moved westward, toward the radar. As for the Finland radar, we interpret this entire zone of velocity oscillations as ground scatter.

The most likely explanation of the low velocity bands seen by both radars is that the ground scatter signal is experiencing a Doppler shift during each traversal through the ionosphere, for example, in response to motion of the ionospheric plasma. The Doppler shifts are periodic and commence at the same time as the negative solar wind pressure pulse would reach the ionosphere. To investigate this further, we next consider results from the vertical incidence Doppler sounder experiment, DOPE.

\subsection{HF Doppler sounder and digisonde}

DOPE recorded ionospheric Doppler oscillations on this day at the same time as the Doppler oscillations measured by CUTLASS. This is apparent in Fig. 4, which displays stacked velocity-time plots for selected Iceland East and Finland range gates, and Doppler shift-time plots for the O-mode from DOPE. The DOPE X-mode record is similar to the Omode and therefore not shown. Note the different ordinate axis scales for each panel. The two large oscillations commencing near 09:30 UT are particularly prominent, and further oscillations occur later in all traces. The two Finland ionospheric scatter plots in the second panel show auroral oval features at $75.2^{\circ}$ and $77.0^{\circ}$ magnetic latitude, whereas the plots in the third panel are for the Finland ground scatter near $69.2^{\circ}$ and $69.5^{\circ}$ magnetic latitude. 


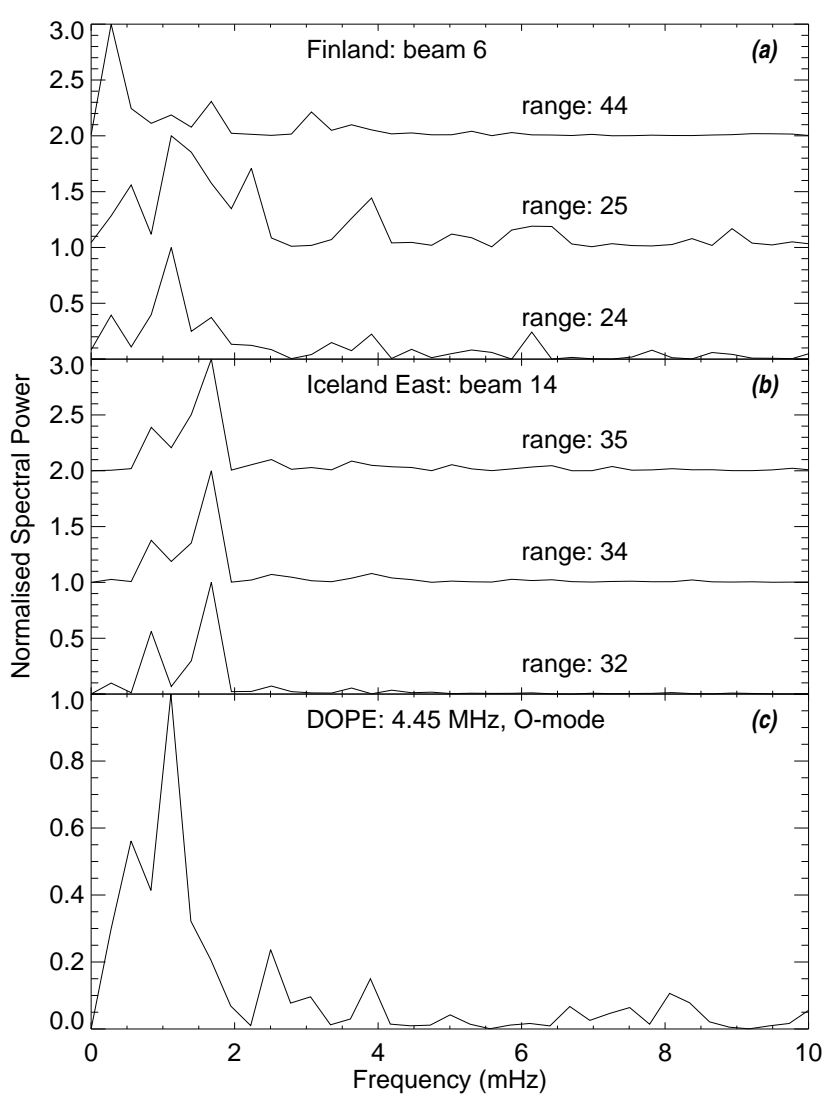

Fig. 5. Stacked power spectra $(0.3 \mathrm{mHz}$ resolution), over 10:2011:20 UT, for (a) Finland beam 6 radar velocities (b) Iceland beam 14 radar velocities, and (c) DOPE vertical incidence Doppler shifts.

Ionograms from the Troms $\varnothing$ dynasonde show that for vertical incidence, the $4.45 \mathrm{MHz} \mathrm{O}$-mode group height was $\sim 260-265 \mathrm{~km}$ over this interval, with $f o \mathrm{~F} 2 \sim 5.4 \mathrm{MHz}$. The ionosphere did not appear to be particularly disturbed before 13:00 UT, and the DOPE oscillations were observed from just below the peak of the F2-region.

Power spectra of the Finland, Iceland East and DOPE Doppler oscillations over the interval 10:20-11:20 UT (i.e. from the end of pressure pulse - labelled "D" in Figs. 2b and 3 , and covering the first half of the pressure oscillations) are compared in Fig. 5, for most of the range bins presented in Fig. 4. The DOPE data were low pass filtered at $11 \mathrm{mHz}$ and the spectra were computed with a single FFT then normalized to facilitate comparison. Resolution of all the spectra is about $0.3 \mathrm{mHz}$. The Iceland East ground scatter spectra (Fig. 5b) show a clear peak $\sim 1.7 \mathrm{mHz}$ at ranges corresponding to the low velocity backscatter pulsations. The Finland plots (panel a) is more complicated, with extra spectral features present. This is not surprising for the auroral oval ionospheric scatter (range gate 44). Finland beam 6, ranges 24 and 25 and DOPE (panel (c)) are essentially looking at the same part of the ionosphere and show prominent spectral peaks near $1.1 \mathrm{mHz}$. Finland beam 6 , range gate 24 also shows a secondary peak at $1.7 \mathrm{mHz}$. Note also the small peaks around $6-8 \mathrm{mHz}$ present in the Finland ground scat-

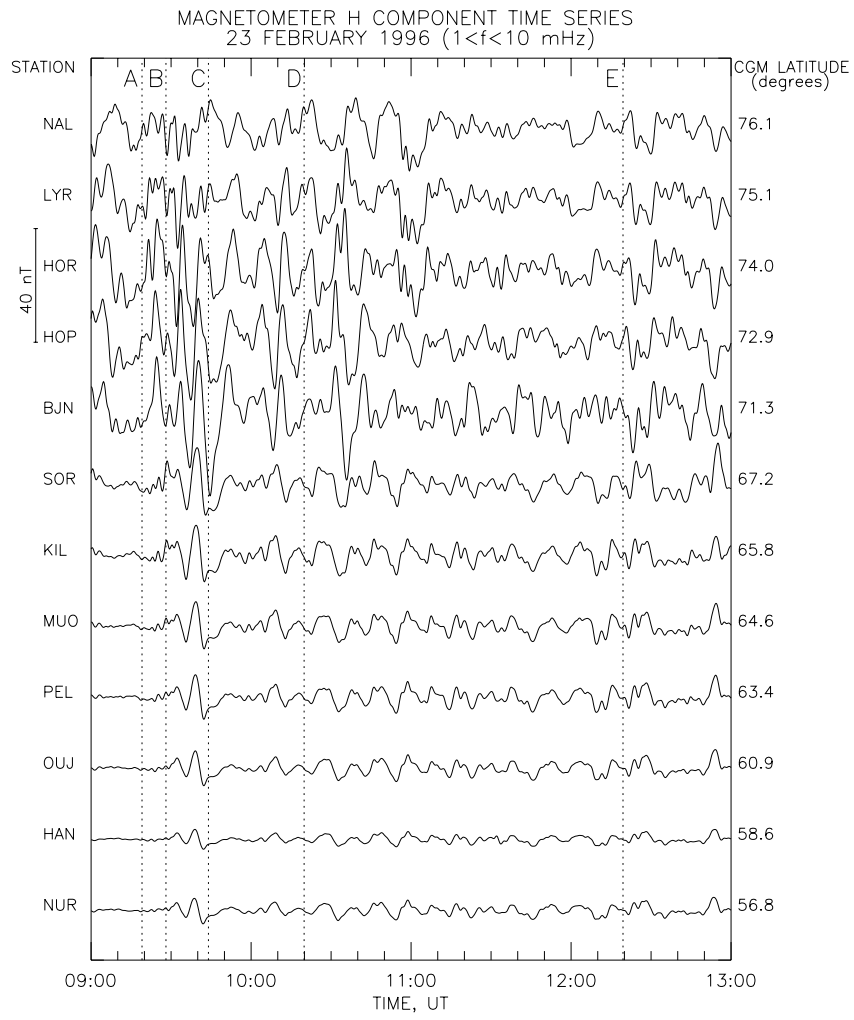

Fig. 6a. Magnetometer $H$-component data from the IMAGE and SAMNET arrays, 23 February 1996. Time series records for 09:0013:00 UT. Vertical dotted lines indicate approximate arrival times at the ionosphere of events labelled "A" to "E" in Figs. 2 and 3.

ter and DOPE spectra.

\subsection{Ground magnetometer data}

Figure 6a presents stacked $H$-component time series plots from representative IMAGE and SAMNET magnetometer stations for 09:00-13:00 UT (covering the IMF $B_{z}$ southward turning, the solar wind pressure pulse, and the arrival of oscillations at the ionosphere), band-pass filtered between 1 and $10 \mathrm{mHz}$. Vertical dotted lines, labelled "A" to "E", indicate arrival times at the ionosphere of the features identified in Figs. 2a and 3. Figure $6 \mathrm{~b}$ is a higher resolution plot showing the $H$ - and $D$-components (solid and dotted lines, respectively) over 09:10-10:10 UT (covering the IMF $B_{z}$ southward turning and the solar wind pressure pulse arrival at the ionosphere) for the same stations.

All stations recorded a large bipolar event starting around 09:30 UT, coincident with the presumed arrival at the ionosphere of the solar wind pressure pulse (recall that because we assumed a uniform propagation time, the solar wind pressure decrease labelled "B" actually reaches the ionosphere around 09:30 UT). This was followed for some hours by Pc5 pulsation activity that was remarkably similar at all stations $<74^{\circ}$ latitude. The amplitude of these pulsations appears to 


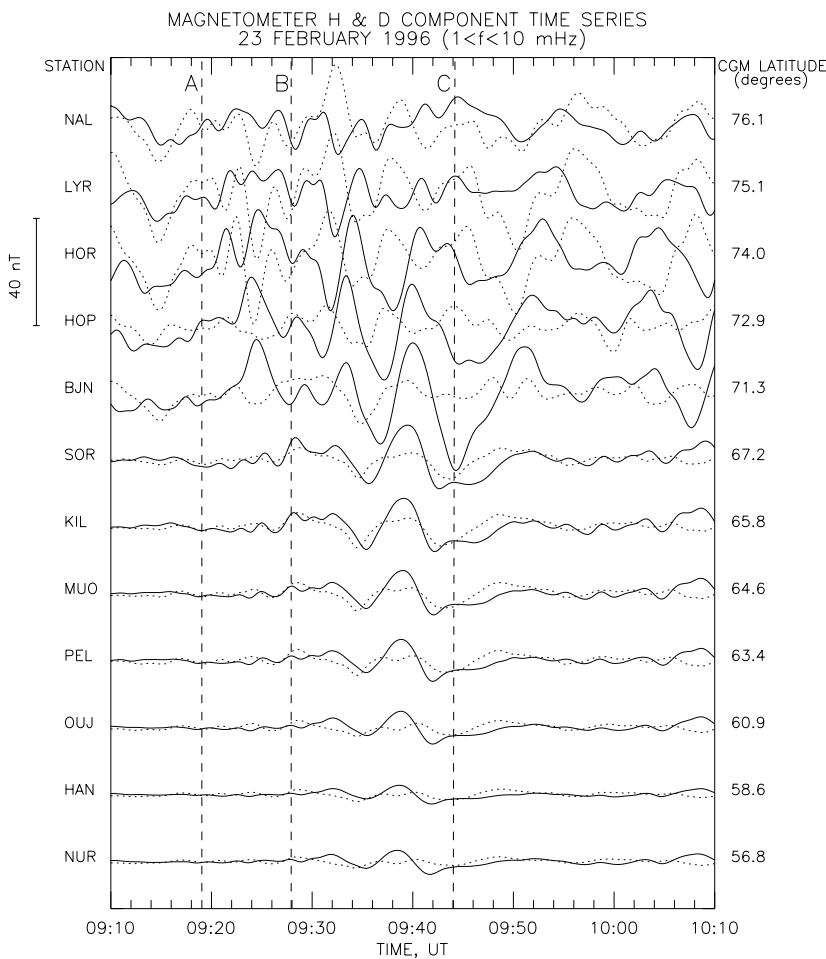

Fig. 6b. Expanded time series records for 09:10-10:30 UT, where $H$-component is the solid line and $D$-component is the dotted line. Vertical dashed lines indicate events identified earlier.

peak, and the phase seems to change, between SOR $\left(67.2^{\circ}\right)$ and BJN $\left(71.3^{\circ}\right)$ latitude. The magnetometer time series also show two transient, pulse-like events starting around 09:20 UT at $\sim 74^{\circ}$ magnetic latitude (HOR), coincident with the southward turning of $B_{z}$ reaching the ionosphere. The pulses are clearest in the $H$-component and appear somewhat later at other latitudes. At this time shorter period (frequency 6-8 $\mathrm{mHz}$ ) pulsations commenced at lower latitudes. These were most prominent $\sim 66-67^{\circ}$ latitude.

Stacked power spectra for the same magnetometer $H_{-}$ components are presented in Fig. 6c. This is the same time interval shown in Fig. 5, although similar features were present for some hours in the magnetometer spectra. The spectra in Fig. 6c were weighted by $f^{1.0}$, to better display higher frequency features, and normalized to facilitate comparison. Spectral resolution is $\sim 0.3 \mathrm{mHz}$. The spectra show a clear peak around $1.6-1.7 \mathrm{mHz}$ at all stations $<75^{\circ}$ latitude. Smaller peaks $\sim 6-8 \mathrm{mHz}$ are also present at many stations.

Signals at the highest latitude stations (HOR, LYR and NAL, 74-76 ${ }^{\circ}$ magnetic latitude) have more high frequency activity and are somewhat different in appearance to the lower latitude signals. This suggests they are probably associated with the dayside auroral oval and open/closed field line boundary, in agreement with the CUTLASS and DMSP observations discussed earlier.

We now consider the $1.6-1.7 \mathrm{mHz}$ magnetic pulsations in more detail. The variation in amplitude, phase, ellipticity and azimuth with geomagnetic latitude for this frequency is

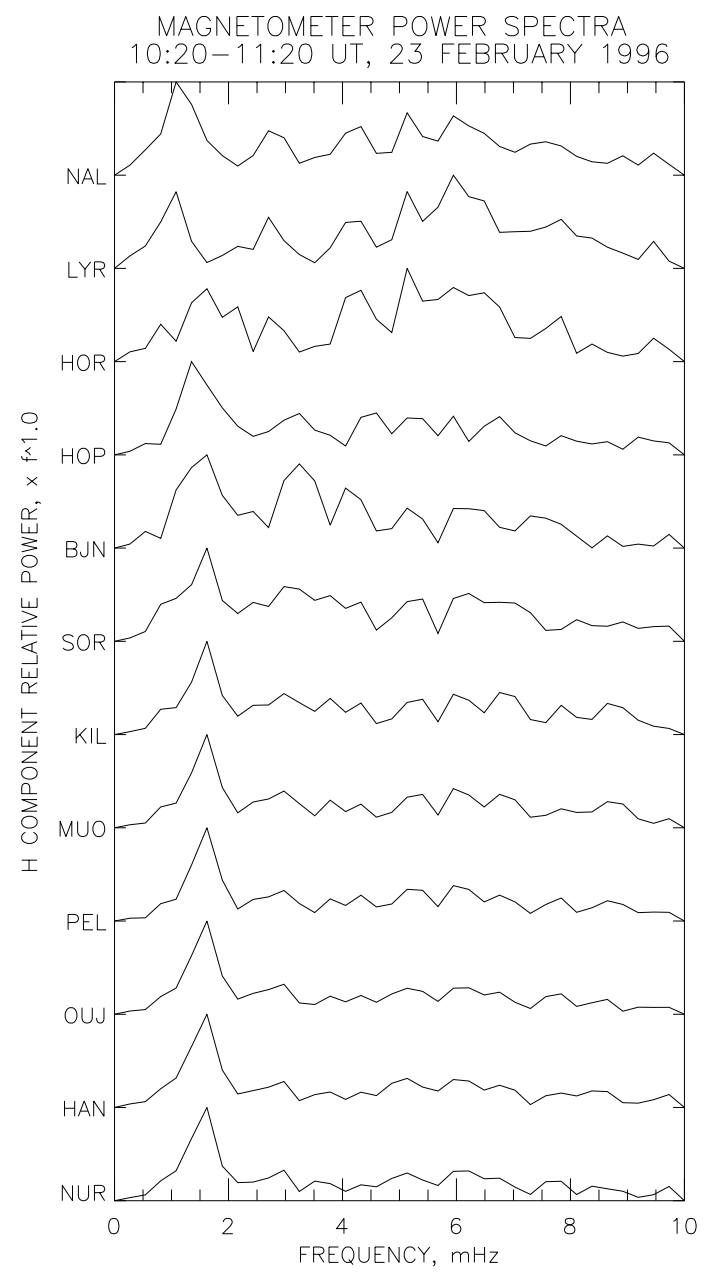

Fig. 6c. Power spectra for 10:20-11:20 UT (resolution is $0.3 \mathrm{mHz}$ ). Spectra were weighted by $f^{1.0}$ and normalized.

shown in Fig. 7. These measurements were obtained using complex demodulation (Beamish et al., 1979; Chisham and Mann, 1999) over a bandwidth of $1.5-2.3 \mathrm{mHz}$, yielding a demodulate value each $12 \mathrm{~min}$. The points plotted in Fig. 7 are for the time interval centred on 10:36 UT, but other times give similar results. The plots show a peak in amplitude, a reversal in phase, and linear generally north-south polarization, all consistent with a field line resonance (FLR) around 72 $73^{\circ}$ geomagnetic latitude. The dotted vertical line near $73^{\circ}$ indicates the latitude of the amplitude peak. The full width at half power (FWHP) of the amplitude-latitude profile indicates a resonance scale size at the ground of the order of $4^{\circ}$ in latitude, i.e. $\sim 400 \mathrm{~km}$.

Azimuthal wave numbers $m$ were determined using Dcomponent data for stations near $66.1^{\circ}$ and also near $63.6^{\circ}$ geomagnetic latitude. These wave numbers are of the order of -5 to -8 at $09: 48 \mathrm{UT}$, reducing to 0 to +1 at 10:36 UT, and -2 at 11:00 UT. Negative $m$ numbers denote westward propagation. The azimuth angles equatorward of the resonance are generally directed north-east earlier in the day and rotate to northwest after noon. 


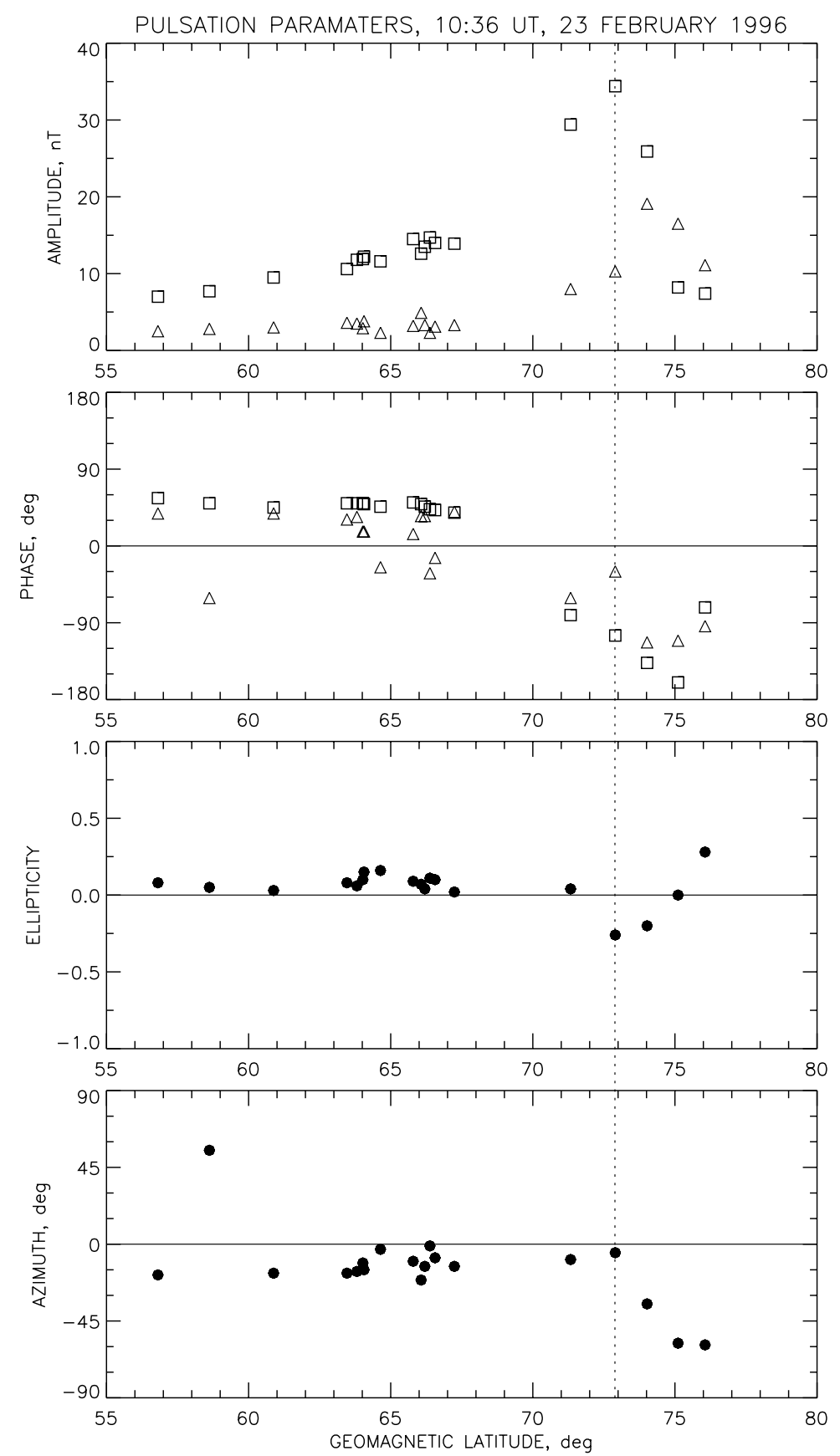

Fig. 7. Variation in amplitude (top panel), phase, ellipticity and azimuth angle (bottom) for $1.6 \mathrm{mHz}$ geomagnetic pulsations at 10:36 UT on 23 February 1996. In the upper two panels squares denote $H$-component values and triangles $D$-component.

Using IMAGE data, Mathie et al. (1999b) showed that discrete FLRs occur at the eigenfrequency of the continuum determined from the cross-phase between pairs of adjacent magnetometer stations (Waters et al., 1995). We measured the field line eigenfrequency in this way (Menk et al., 2001) and during the morning of 23 February, it varied smoothly from $1.6 \pm 0.3 \mathrm{mHz}$ at $71.4^{\circ}$ latitude, to $8.0 \pm 0.3 \mathrm{mHz}$ at $66^{\circ}$, and $15 \pm 1 \mathrm{mHz}$ at $62^{\circ}$. Complex demodulation plots in the same format as Fig. 7 but for a frequency of $8.0 \mathrm{mHz}$ show a small peak in power, a reversal in phase and changes in ellipticity and azimuth characteristic of a FLR, near $66^{\circ}$ latitude.

Cross-phase measurements can be used to estimate the width, $Q$ and damping of the resonance (Menk et al., 1999). For the $1.6-1.7 \mathrm{mHz}$ signal the resonance width in the ionosphere is thus estimated at $90-150 \mathrm{~km}$, the $Q$ is 1.5 to $>3$, and the damping factor $\sim 0.3$. We could not obtain a crossphase resonance signature at $\geq 75^{\circ}$ latitude. This is indicative of open field lines at these latitudes (Ables et al., 1998).

\subsection{Imaging riometer observations}

Data from the Kilpisjärvi imaging riometer were inspected in the form of power-time and absorption-time plots, and colour absorption maps. The latter represent the projection 


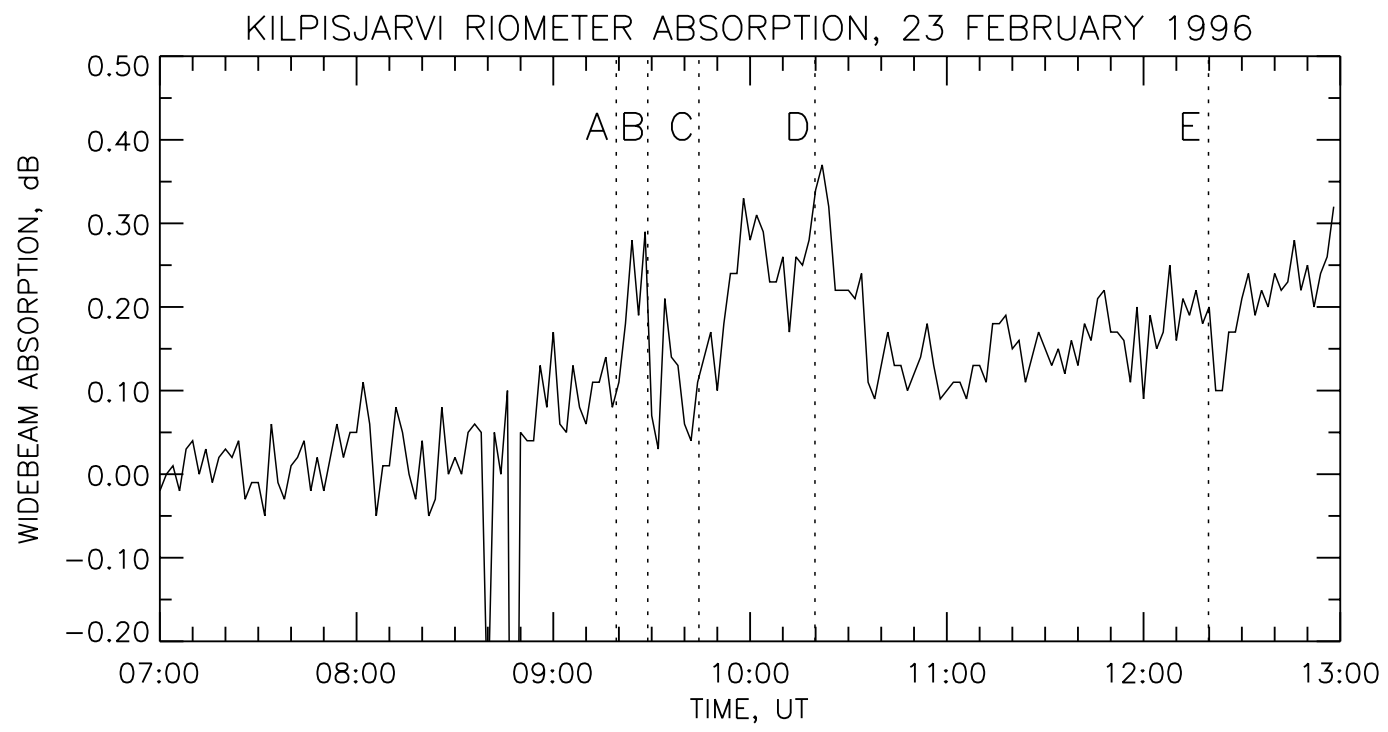

Fig. 8. Cosmic noise absorption over 07:00-13:00 UT for the wideband KIL riometer. Resolution is 0.05 dB. Vertical dotted lines indicate approximate arrival times at the ionosphere of events labelled "A" to "E" in Figs. 2 and 3.

to $90 \mathrm{~km}$ altitude of cosmic noise absorption over a square $240 \times 240 \mathrm{~km}$ area, measured each 15 or $120 \mathrm{~s}$. The IRIS facility also includes a widebeam riometer, with a $-3 \mathrm{~dB}$ beamwidth of $\sim 94^{\circ}$. Figure 8 shows the variation in received power over 07:00-13:00 UT, measured with the widebeam riometer. For brevity other beams and absorption maps are not shown here, but they indicate the same general features. The dotted vertical lines in the figure denote the arrival times at the ionosphere of the events discussed earlier, including the southward $B_{z}$ turning at 09:19 UT ("A") and the initial solar wind pressure decrease near 09:28 UT ("B"). A sudden increase in absorption (i.e. decrease in received signal power), commencing at 09:19 UT, was followed at 09:28 UT by a decrease in absorption, lasting $\sim 20 \mathrm{~min}$. Enhanced absorption between $\sim 09: 50-10: 35$ UT coincides with the solar wind pressure minimum in Fig. $2 \mathrm{a}$.

\section{Discussion}

\subsection{Effects of solar wind variations}

In this paper we are principally concerned with the responses of the ionospheric sounders and magnetometers to the sudden decrease in solar wind pressure arriving at 09:30 UT. This was preceded by a southward turning of $B_{z}$ at 09:19 UT, although $B_{z}$ had been negative for about $45 \mathrm{~min}$ just before then and IMF conditions conducive to dayside reconnection occurred throughout the interval under consideration.

Inspection of Fig. 3 and high resolution velocity-time plots not given here show that two narrow poleward moving flow bursts were recorded by the Finland radar between 09:2009:30 UT. These started near $76^{\circ}$ latitude and extended to $79^{\circ}$ latitude at a rate of $\sim 1.5-2 \mathrm{~km} \mathrm{~s}^{-1}$, while the flow velocity within the flow channels was $\sim 1.0 \mathrm{~km} \mathrm{~s}^{-1}$. The high reso- lution magnetometer time series in Fig. $6 \mathrm{~b}$ shows that near the same time, a pair of pulses was observed at HOR $\left(74.0^{\circ}\right.$ geomagnetic latitude), appearing somewhat later at other latitudes. Taking into account the longitudinal spread of the stations (HOR is westward of HOP), the data suggest the pulses were travelling mostly eastward at $1.5-3 \mathrm{~km} \mathrm{~s}^{-1}$. This was followed at lower latitudes by $6-8 \mathrm{mHz}$ pulsations. A sudden increase in cosmic noise absorption was recorded by the riometer at $65.8^{\circ}$ latitude between 09:20-09:30 UT.

These observations are consistent with the ionospheric signatures of reconnection at the magnetopause (e.g. Pinnock et al., 1993; Øieroset et al., 1997). In particular, southward $B_{z}$ turnings are connected with flux transfer events (FTEs). SuperDARN radar observations of the cusp have shown that the ionospheric footprint of FTEs is characterised by pulsed poleward moving flow bursts, known as pulsed ionospheric flows (PIFs) or flow channel events (FCEs), near the polar cap boundary (Pinnock et al., 1995; Provan et al., 1998; Provan and Yeoman, 1999; Neudegg et al., 1999; McWilliams et al., 2000). The relationship between PIFs, FCEs and FTEs is discussed more thoroughly in Wild et al. (2001). A detailed discussion of the mapping of FTEs to the ionosphere in PIFs appears in McWilliams et al. (2001).

The poleward flow bursts in the Finland velocity plot are similar in appearance to reported PIFs and commenced when $B_{z}$ turned southward at 09:19UT, about $10 \mathrm{~min}$ before the solar wind pressure pulse. The equatorward boundary of the high velocity region is $\sim 76^{\circ}$ and near the likely ionospheric footprint of the open/closed field line boundary (Rodger and Pinnock, 1997; Milan et al., 1998). This agrees with the radar spectral width, DMSP and magnetometer observations. Similarly, the magnetometer observations are consistent with the predicted appearance and motion of the ground signature of FTEs under $B_{y}$ negative conditions in the Northern Hemi- 


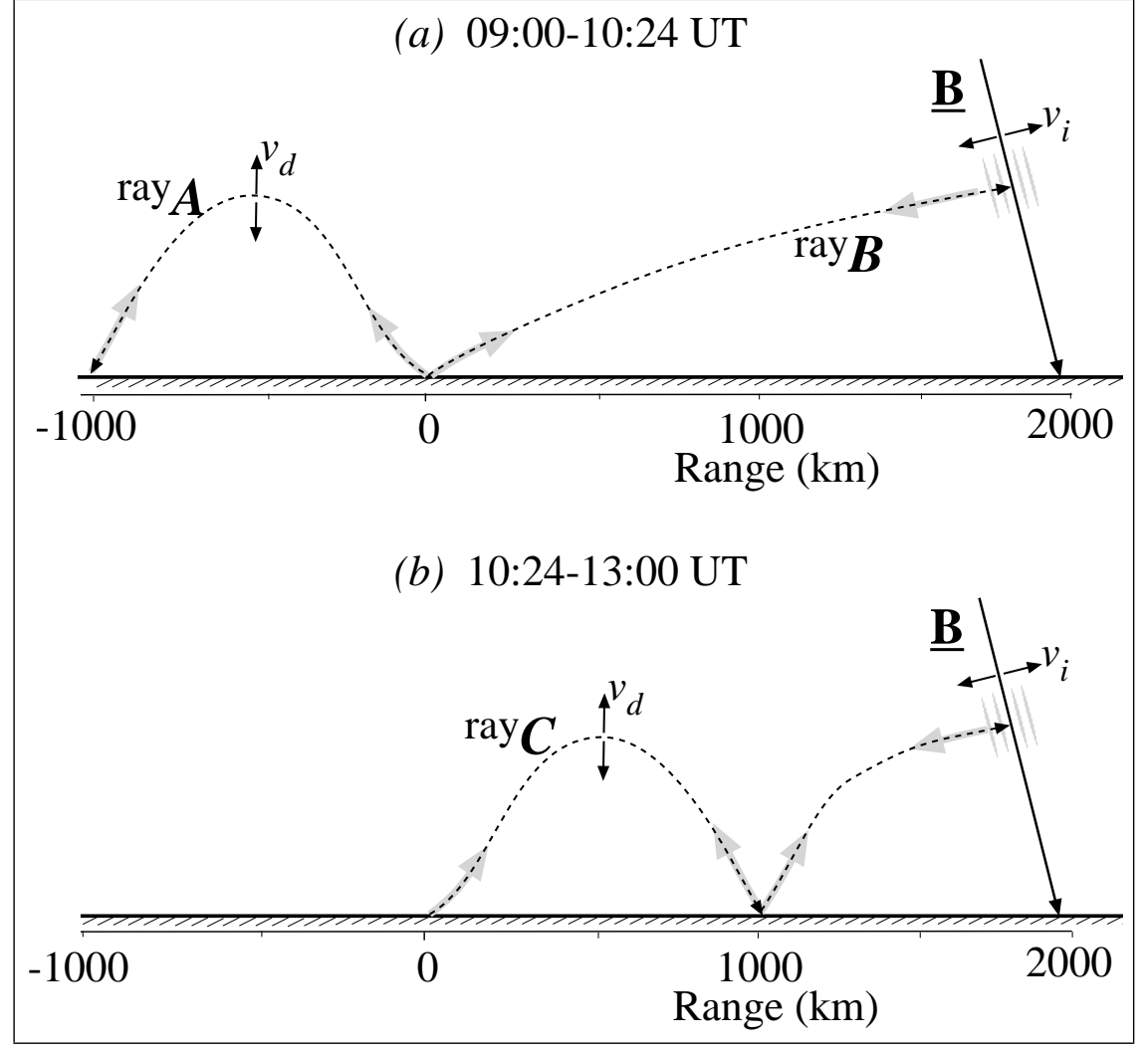

Fig. 9. Likely ray paths for the Finland radar. (a) 09:00-10:24 UT. Ray A represents ground scatter reflected from the F-region behind the radar, and experiencing ionospheric Doppler oscillations $v_{d}$. Ray B represents ionospheric scatter from the cusp F-region, with line-ofsight Doppler velocity $v_{i}$.

(b) 10:24-13:00 UT. Ray C represents simultaneous F-region reflected ground scatter and 1.5 hop mode ionospheric scatter from the auroral F-region. sphere (Southwood, 1987; Chaston et al., 1993; Provan et al., 1998).

The sudden decrease in solar wind pressure commencing at 09:30 UT then appeared to enhance the flow bursts, triggered F-region Doppler oscillations, initiated $1.6-1.7 \mathrm{mHz}$ magnetic pulsations with a large bipolar event, and caused a reduction in riometer absorption. The flow bursts, Doppler shifts and magnetic pulsations occurred over a wide region, lasted for some hours, and exhibited the same period as solar wind pressure fluctuations. The IMF $B_{z}$ component was southward throughout the pressure decrease, and shows some fluctuations but at a higher frequency than observed on the ground (Fig. 2b). Thus, while conditions were favourable for reconnection, and the radar cusp region flow channels appear to be reconnection related, it is the changes in solar wind pressure that seem to be driving the ionospheric and magnetic perturbations.

\subsection{Properties of the ionospheric oscillations}

Here we discuss the spatial variation in phase and the location, scale size and direction of motion of the ionospheric oscillations. We first consider phase motion of the oscillatory features in the Finland Doppler velocity record. For this purpose we determined the phase delays at several times after 10:30 UT, using stacked velocity-time plots and phase spectra (not shown here) for several range gates in beam 6 .

For the ground scatter velocity oscillations the phase delays suggest the oscillations (which are being observed mostly equatorward of the FLR) are moving poleward at 1$5 \mathrm{~km} \mathrm{~s}^{-1}$. This sense of motion is consistent with the change in phase of magnetic pulsations associated with resonance (Walker et al., 1979). Milan et al. (1997a) pointed out that the CUTLASS radars can observe ground scatter from both in front of the radar and from behind the radar, in a rear lobe of the antenna pattern. Accordingly, Milan et al. (1998) argued, from an analysis of radar elevation angles, that ground scatter observed at Finland before 10:24 UT on this day is from behind the Finland radar. This time is identified by the dashed line on Fig. 3b. Returns are obtained from behind the radar due to the low F-region electron density in the high-latitude winter ionosphere compared to lower latitudes. However, between 10:24 UT and 14:00 UT, the high-latitude F-region electron density increased sufficiently so that ground scatter from in front of the radar is of higher backscatter power and hence dominates. A similar analysis of elevation angles demonstrates that the ground scatter from Iceland (Fig. 3d) is from in front of the radar.

Motion of the ionospheric backscatter flow bursts (associated with the auroral oval) over the times of interest are also generally poleward, at $2-3 \mathrm{~km} \mathrm{~s}^{-1}$. Prikryl et al. (1998) observed similar properties for flow channel events associated with solar wind pressure fluctuations. They found similar discrete frequencies in power spectra of ULF waves on the ground, magnetic field variations recorded by GOES, GEOTAIL and WIND, and ionospheric velocity oscillations in HF radars. This led them to argue that the convection velocity oscillations were controlled by the oscillating solar wind- 
magnetosheath magnetic and electric fields at the dayside magnetopause, while FLRs were excited on magnetic shells adjacent to the noon magnetopause.

For the Iceland East radar the Doppler velocity ground scatter oscillations (Fig. 3d) appear to move westward before about 11:00 UT, and eastward, or have no net east-west motion afterward. The speed is variable, corresponding to an azimuthal wave number of the order of -2 to -5 before 11:00 UT. This agrees well with the magnetometer measurements. Inspection of Fig. 4 and higher resolution plots not given here shows that the ionospheric oscillations are in phase, or nearly in phase, in the Finland, Iceland East and DOPE echoes.

Now we consider the location where the radar oscillations are observed. Figure 9a shows the likely ray-path geometry for the CUTLASS Finland beam between about 09:00 UT and 10:24 UT (including the southward turning - "A" in Fig. $2 \mathrm{a}-$ and the solar wind pressure pulse reaching the ionosphere). Information on identifying the ray paths comes from the different properties of ionospheric and ground scatter, as described earlier, and from interferometer measurements of elevation angle (Milan et al., 1997a, b, 1998). Following the earlier discussion on the location of the ground scatter, ray A represents the ground scatter return reflected from the Fregion behind the radar, and ray $\mathrm{B}$ represents the F-region ionospheric scatter. Motions in the cusp ionosphere are indicated by the orthogonal velocities $v_{i}$. Since the calculation of range is based on time of flight, the ionospheric Doppler oscillations $v_{d}$ in ray A will occur at approximately half the distance indicated on the range-time plots. The same will apply to the Iceland East ground scatter observations. These ionospheric target regions are represented by the shaded boxes in Fig. 1, and span $64-68^{\circ} \mathrm{N}$ geographic for the Finland radar, and 16 to $1^{\circ}$ geographic longitude for Iceland East.

After $\sim 10: 24$ UT high elevation angles in the Finland returns for larger ranges (see Milan et al., 1998) suggest the ray path shown in Fig. 9b. This mode, ray C, provides simultaneous F-region reflected ground scatter and 1.5 hop ionospheric scatter from the auroral F-region. High velocity Pc5 features have been reported previously in HF radar data at slightly lower latitudes (Yeoman et al., 1990b, 1997) and in the cusp (Matthews et al., 1996), although not in the context of 1.5 hop returns as discussed here.

The ground scatter Doppler shift regions for the two radars are separated by several hundred $\mathrm{km}$ and indicate that the ionospheric oscillations span at least $25^{\circ}$ in longitude. In addition, the observation of ground scatter from behind the Finland radar before 10:24 UT indicates that the oscillations extend over at least $16^{\circ}$ in latitude. The magnetometer observations also showed that the pulsations extend over at least $20^{\circ}(2200 \mathrm{~km})$ in latitude. The magnetometer observations in Fig. 7 and the cross-phase analysis show that the $1.6-1.7 \mathrm{mHz}$ resonance region is around $72-$ $73^{\circ}$ magnetic latitude (HOP, HOR, BJN). The $1.6-1.7 \mathrm{mHz}$ ionospheric Doppler oscillations were observed 6-7 $7^{\circ}(660$ $770 \mathrm{~km}$ ) equatorward of this region. Wright et al. (1998) had previously reported the appearance of Pc5 pulsations in the ionosphere, up to $8^{\circ}$ equatorward of a broad FLR identified using the IMAGE magnetometer array.

Finally, we consider the ionospheric velocity vectors for the ground scatter, $v_{d}$ for ray A before 10:24 UT and ray $\mathrm{C}$ after 10:24 UT. We assume that (a) the Finland and Iceland East radars and DOPE are examining the same altitude in the ionosphere, and (b) the radar and DOPE Doppler shifts are due solely to vertical motions of the reflection point. Furthermore, note that rays $\mathrm{A}$ and $\mathrm{C}$ in Fig. 9 traverse the Doppler shift region twice, so the resultant velocity should be halved.

Under these assumptions, the largest amplitude Doppler velocity oscillations observed by the CUTLASS radars each correspond to peak velocity components of about $\pm 10 \mathrm{~m} \mathrm{~s}^{-1}$, and the DOPE Doppler oscillations to $\pm 30 \mathrm{~m} \mathrm{~s}^{-1}$ vertically, with equivalent motions of the reflection point of a few $\mathrm{km}$. Although assumption (b) ignores the effects of redistribution of plasma or changing magnetic field, it is instructive to estimate the Doppler shifts that would result from particle motions driven by downgoing transverse Alfvén waves. If the velocity and magnetic field perturbations are linearly related, then (Rishbeth and Garriott, 1964)

$$
\Delta V \approx \frac{\Delta B}{\sqrt{\mu_{0} \rho}} \sqrt{\frac{\omega}{v_{i n}}},
$$

where $\rho$ is the mass density of the F2-region plasma (comprising mostly $\mathrm{O}^{+}$ions at a concentration of $\sim 3 \times 10^{11} \mathrm{~m}^{-3}$ ), $\omega$ is the angular frequency of the pulsation, and $v_{i n}$ is the ionneutral collision frequency in the F-region, $\sim 1 \mathrm{~s}^{-1}$. Hence, for $\Delta B \sim 10 \mathrm{nT}$ (assuming no attenuation between the between the ionosphere and the ground) and $\omega \sim 0.01 \mathrm{rad} \mathrm{s}^{-1}$, we have $V \sim 10 \mathrm{~m} \mathrm{~s}^{-1}$, comparable to the magnitude of the observed Doppler oscillations.

These observations highlight the ability of ground scatter measurements to extend the scope and capability of HF radars for monitoring perturbation features in the ionosphere. We note in this regard that auroral backscatter radars (such as STARE) are limited by the threshold for the formation of irregularities, which is of the order of $15-20 \mathrm{mV} \mathrm{m}^{-1}$ (Cahill et al., 1978). Importantly, downgoing fast (compressional) mode waves are characterised by small ionospheric electric fields (Kivelson and Southwood, 1988; Yeoman and Lester, 1990), and are, therefore, more readily detected using ground scatter measurements.

Poole et al. (1988) showed that three separate mechanisms contribute to pulsation-driven ionospheric Doppler oscillations, while Sutcliffe and Poole (1989) gave a detailed discussion of the validity of the $\boldsymbol{E} \times \boldsymbol{B}$ mechanism (their $V_{2}$ mechanism). Sutcliffe and Poole's (1989) predicted Doppler velocities vary strongly with height near the E- and F-region peaks; this is the reason for assumption (a). However, the Poole et al. (1988) modelling assumes purely transverse shear Alfvén mode downgoing waves. This may not be the case some distance away from the resonance latitude, such as in our situation here, where the downgoing waves are likely to be a mix of shear Alfvén and fast modes. Modelling of ULF wave effects in the ionosphere at low-latitudes (Waters et al., 2001) indicates that the HF Doppler oscillations due 
to downgoing fast mode waves are smaller than for shear Alfvén mode waves. Therefore, it is difficult to anticipate the ionospheric velocities we would expect to see here, but the inferred velocity components probably represent an upper bound on the real case.

\subsection{Pulsation source mechanism}

The magnetometer and radar observations show $1.6-1.7 \mathrm{mHz}$ pulsations with similar appearance over at least $20^{\circ}$ in latitude and $25^{\circ}$ in longitude. These were triggered initially by the solar wind pressure pulse, and continued for some hours. The solar wind dynamic pressure was variable during that time, with a spectral peak $\sim 1.6 \mathrm{mHz}$ (Fig. 2b). The IMF was also variable, with spectral peaks around $1.6 \mathrm{mHz}$ in $B_{y}$ and $2.1 \mathrm{mHz}$ in all three components. Since transient fluctuations are often present in the solar wind pressure and IMF, caution is needed when interpreting such spectra. However, significant transients do not seem to be present during the interval considered, except in $B_{y}$. The extended interval of 1.6$1.7 \mathrm{mHz}$ ionospheric and magnetic oscillations is, therefore, most likely due to (a) periodic solar wind pressure variations, (b) periodicity in the reconnection rate, or (c) some combination of these mechanisms. The most likely explanation of the spatial extent of the observations is that one or both of these mechanisms launched fast mode waves into the magnetosphere, driving resonances where the field line eigenfrequency and incoming wave frequency match, and forced field line oscillations elsewhere (Hasegawa et al., 1983). Complex demodulation (Fig. 7) and cross-phase analysis demonstrates that the pulsations coupled to FLRs around $72-73^{\circ}$ geomagnetic latitude, equatorward of the predominantly reconnection driven flows at $74-80^{\circ}$.

Solar wind impulse-driven pulsations can have similar signatures to localized field line reconnection events (Farrugia et al., 1989; Sibeck, 1990). In our data, a reasonably localized pulse occurred at 09:19 UT (the southward $B_{z}$ event) at latitudes near $74^{\circ}$, where the Finland radar observed reconnection related flows. This propagated relatively slowly to other latitudes. In contrast, the pressure decrease at 09:30 UT produced a bipolar response at more widely spaced locations than the reconnection events, and was followed by sustained Pc5 signals driven at the same frequency as the solar wind pressure oscillations.

Yeoman et al. (1997) presented high resolution measurements of $7-8 \mathrm{mHz}$ magnetic pulsations recorded with IMAGE magnetometers, and simultaneous CUTLASS Finland backscatter velocity oscillations of magnitude 100$300 \mathrm{~m} \mathrm{~s}^{-1}$. The pulsations were most probably due to an impulse-driven cavity/waveguide resonance, which coupled to FLRs whose width in the ionosphere over Troms $\varnothing$ was of the order of $60 \mathrm{~km}$. Such a small scale-size means that the FLR is highly attenuated in the ground magnetometer data. Our signals have considerably larger scale size, although the cross-phase measurements, which are based on the difference between signals at adjacent stations, yielded a smaller scale size $(70-90 \mathrm{~km})$ than the FWHM measure- ments $(\sim 400 \mathrm{~km})$. This may reflect the effects of spatial integration on the magnetometer signal (Poulter and Allan, 1985). The estimated damping factor of 0.3 points to the existence of damping mechanisms other than Joule dissipation (Yeoman et al., 1997).

Solar wind pressure pulses of the magnitude observed here are believed to be fairly common (Sibeck, 1990). Groundbased observations associate them with ringing type magnetic pulsations with periods of a few minutes (Takahashi et al., 1988; Farrugia et al., 1989; Sibeck, 1990), including field line resonances (Potemra et al., 1989; Warnecke et al., 1990; Parkhomov et al., 1998; Prikryl et al., 1998).

Examining a large magnetospheric compression event, Takahashi et al. (1988) found

(i) $1.1-1.7 \mathrm{mHz}$ compressional waves which could have been due to a global fast-mode cavity resonance,

(ii) standing 3-6 mHz Alfvén waves (i.e. FLRs), and

(iii) $3-8 \mathrm{mHz}$ irregular disturbances near the magnetopause.

The magnetopause and bow shock also seemed to execute 1.1-1.7 mHz motions. Potemra et al. (1989) also found that quasi-periodic variations in the solar wind density may drive transient magnetospheric ULF waves at the same frequency. These may excite local FLRs. Takahashi et al. (1988) believed the frequency of the $1.1-1.7 \mathrm{mHz}$ compressional wave was too low to couple to standing Alfvén waves. However, Mathie et al. (1999 a, b) demonstrated the existence of $1.7 \mathrm{mHz}$ field line resonances at high-latitudes, and discussed their origin in terms of magnetospheric waveguide modes.

Farrugia et al. (1989) have shown that magnetic oscillations may be observed over a wide range of latitudes and longitudes with the same frequency as magnetopause motions. The meridional motion of the signals across the ground corresponds to tailward propagation in the magnetosphere, at $\sim 11 \mathrm{~km} \mathrm{~s}^{-1}$. Sibeck (1990) presented a detailed description of this process. Significantly, large amplitude solar wind dynamic pressure impulses, recurring on time scales of 5$15 \mathrm{~min}$, are a fairly common feature just upstream of the bow shock. The ground signatures of these pressure pulses include bipolar north-south flows and magnetic perturbations at high-latitude stations. This is very similar to what we have seen for the event studied here. For example, a prominent feature of Fig. 3 is the two velocity features in the Finland radar, associated with north-south flows in the cusp and Fregion Doppler oscillations at lower latitudes, triggered by the solar wind pressure pulses at 09:30 UT. Similarly, the presence of bipolar magnetometer pulses evident in Fig. $6 \mathrm{~b}$ agrees with the response to sudden expansions predicted by Araki and Nagano (1988).

Sibeck (1990) predicted the appearance of increased cosmic noise absorption and ELF/VLF activity accompanying sudden sharp increases in solar wind dynamic pressure. The Kilpisjärvi riometer data showed a sudden increase in absorption near 09:20 UT ("A" in Fig. 8), consistent with the precipitation of a particle burst associated with an FTE. This 
was followed by a decrease in absorption while the solar wind pressure was decreasing. This is also reasonable, since the resultant sudden magnetospheric expansion (rather than a compression, as discussed by Sibeck) would distribute the population of energetic electrons over a larger volume, thereby decreasing the flux at the ground. The reason for the observed enhancement in absorption while the solar wind pressure was at its minimum is not clear.

Parkhomov et al. (1998) examined geomagnetic pulsations associated with a negative solar wind pressure pulse (by a factor of $\sim 3$ ) and found this initiated $2.3 \mathrm{mHz}$ oscillations across a wide range of latitudes, lasting for about $25 \mathrm{~min}$. These appeared to couple to a $3 \mathrm{mHz}$ FLR, which they argued was the minimum resonance frequency available to incoming $2.3 \mathrm{mHz}$ fast mode waves. They interpreted the $2.3 \mathrm{mHz}$ pulsations in terms of relaxation oscillations of the magnetopause in response to the negative pressure impulse. Their work paralleled an earlier study by Warnecke et al. (1990), who examined large, long-lived Pc5 FLRs associated with a sudden reduction and subsequent variations in solar wind dynamic pressure. The pulsations were most likely driven by antisunward propagating fast mode hydromagnetic waves, which they concluded were due to both magnetopause surface waves and $\sim 1.7 \mathrm{mHz}$ cavity resonances.

In many respects our own observations agree with the results of those previous studies. A striking feature of our results is the similarity of the pulsations across a wide range of latitudes. Power spectra for several intervals during the day show similar characteristics, with the dominant frequency in the same range as the fluctuations in solar wind pressure and IMF. Therefore it seems likely that solar wind perturbations drive fast mode waves into the magnetosphere, which mode convert to transverse Alfvén resonances where the frequencies match, and propagate direct to the ionosphere elsewhere. There the waves drive electron motions causing Doppler shift oscillations, resulting in the appearance of perturbations in $\mathrm{HF}$ radar ground scatter records and HF Doppler experiments.

Our results should also be compared with the study by Matthews et al. (1996) of the response to a strong, sharp increase in dynamic solar wind pressure observed with the Halley HF radar and magnetometer arrays. The pulse initiated $3.3 \mathrm{mHz}$ pulsations seen over $\sim 10^{\circ}$ in latitude and with the characteristics of a FLR near $75^{\circ}$ latitude, in the cusp. Their radar measurements yielded an $m$ number of $\sim 10$, toward the nightside. The pulsations lasted for a few hours, being stimulated by further pressure transients. The pressure pulse caused a sudden equatorward movement of the Halley radar backscatter pattern, followed by strong, quasi-periodic poleward moving features anticorrelated with the magnetometer D component pulsations. Matthews et al. (1996) discussed their observations in terms of magnetopause surface waves triggered by the solar wind impulses. Part of the reason they favoured this mechanism is because the $3.3 \mathrm{mHz}$ pulsations had the largest response at the magnetopause, the $m$ number was reasonably high $(m \sim 10)$, and the resonance properties were weak. In our case the $m$ numbers are lower, the resonance is fairly clear and occurs at least $2^{\circ}$ in latitude, inward of the magnetopause, equatorward of the reconnection related flows observed by the Finland radar. The solar wind pressure in our case is $\sim 2 \mathrm{nPa}$ after the pressure change, while for Matthews et al. (1996) it was $\sim 16-23 \mathrm{nPa}$. Therefore, we do not believe our pulsation observations are due to magnetopause surface modes.

Yeoman et al. (1990b) discussed the radar signature of fast mode waves compared to Alfvénic waves incident on the ionosphere. The fast mode waves, having no parallel current, are associated with only small ionospheric electric fields and hence low Doppler velocities. This is consistent with our observations. Yeoman et al. (1990b) also found that the more "compressive" the wave, the higher the $m$ number (e.g. $\sim 12$ compared to $m \sim 2$ for Alfvénic waves). In our case, the azimuthal wave numbers measured using the IMAGE array $8-10^{\circ}$ equatorward of the resonance ranged from -8 to +1 , changing with local time. The radar observations are also several degrees equatorward of the resonance and relate to wave numbers of the order of -2 to -5 . These values are intermediate and do not rule against the fast mode wave mechanism.

\section{Summary and conclusions}

The results of this study may be summarized as follows:

1. Small Doppler velocity oscillations with frequency around 1.6-1.7 $\mathrm{mHz}$ were observed in F-region ground scatter returns on the Finland and Iceland East SuperDARN radars on 23 February 1996. These observations demonstrate the use of ground scatter to extend the capability and resolution of HF radars. While HF radar ground scatter is characterised by narrow spectral width and small Doppler velocity, the ULF wave electric field in the ionosphere modulates the HF ray reflection height, and this modulation results in a small measurable Doppler velocity being imposed on the ground scatter. This provides new, additional information on the ULF wave field

2. The observed oscillations were initiated by a negative solar wind pressure pulse and persisted for some hours, being observed over $\sim 25^{\circ}$ in longitude. The solar wind pressure exhibited fluctuations with a similar frequency during this time.

3. At longer ranges, above $74^{\circ}$, the Finland radar detected periodic high velocity poleward flow bursts. These were initiated by $B_{z}$ turning negative, about $10 \mathrm{~min}$ before the solar wind pulse, and possibly sustained throughout the observation period by IMF conditions conducive to reconnection. The flow bursts lasted for some hours and have the appearance of PIFs that are the ionospheric signature of FTEs.

4. The spatial variation in phase of the low velocity Doppler oscillations is consistent with magnetic pulsa- 
tions of azimuthal wave number $m=-2$ to -5 observed equatorward of a field line resonance.

5. An HF Doppler sounder beneath the radar beams simultaneously recorded Doppler shift oscillations just below the F2-layer peak with similar frequency and phase to those observed with the radars.

6. Velocity vectors for the Doppler oscillations suggest upper limits of $\pm 10 \mathrm{~m} \mathrm{~s}^{-1}$ horizontally, and $\pm 30 \mathrm{~m} \mathrm{~s}^{-1}$ vertically, corresponding to equivalent motions of the reflection point of a few $\mathrm{km}$.

7. Magnetic pulsations with frequency $1.6-1.7 \mathrm{mHz}$ were recorded across the IMAGE and SAMNET arrays. They were initiated by the solar wind pressure decrease and were coupled to field line resonances $\sim 72-73^{\circ}$ magnetic latitude. Scale size of the resonance was estimated at $70-90 \mathrm{~km}$ in the ionosphere and $\sim 400 \mathrm{~km}$ at the ground. Azimuthal wave number, well equatorward of the resonance, ranged from -8 before local noon to around 0 at noon. The pulsations lasted for a few hours, had the same waveform across at least $20^{\circ}$ in latitude, and a similar frequency to perturbations in the solar wind pressure and IMF $B_{x}$ and $B_{y}$ components.

8. A southward $B_{z}$ turning caused a magnetometer pulse $\sim 74^{\circ}$ latitude, that propagated to lower and higher latitudes at $\sim 1.5 \mathrm{~km} \mathrm{~s}^{-1}$. This was followed by $8 \mathrm{mHz}$ FLRs $\sim 66^{\circ}$ latitude.

9. The decreasing solar wind pressure was associated with a reduction in cosmic noise absorption at the Kilpisjärvi riometer. This is most likely a consequence of the magnetospheric expansion.

10. We conclude that a negative impulse in the solar wind dynamic pressure launched fast-mode compressional waves into the magnetosphere. Ground signatures included a bipolar magnetometer pulse, low velocity perturbations of the ionospheric plasma (observed in radar ground scatter), and Pc5 magnetic pulsations over a wide spatial extent. The fast mode waves coupled to field line resonances near $72^{\circ}$ magnetic latitude. The ground scatter and magnetic oscillations persisted for some hours and were probably stimulated by further smaller amplitude perturbations in the solar wind pressure or IMF. A negative turning of the north-south component of the IMF about $10 \mathrm{~min}$ before the pressure pulse probably triggered magnetic reconnection and FTEs. The latter may be presumed to have continued throughout the data interval as the IMF was conducive to dayside reconnection, resulting in large velocity poleward flows in the auroral ionosphere.

Acknowledgements. CUTLASS is supported by the Particle Physics and Astronomy Research Council (PPARC), UK, the Swedish Institute for Space Physics, Uppsala, and the Finnish Meteorological Institute (FMI), Helsinki. We thank D. K. Milling and
I. R. Mann for providing the SAMNET data. SAMNET is a PPARC facility deployed and operated by the University of York. We also thank Lasse Hakkinen at FMI for the supply of IMAGE data, and all those who help maintain the array. WIND data were made available to the CDAWeb site by K. Ogilvie (SWE) and R. Lepping (MFI) at NASA/GSFC. IRIS is operated by the Department of Communications Systems at Lancaster University (UK), funded by PPARC in collaboration with the Sodankylä Geophysical Observatory. We are grateful to A. Rodger and M. Pinnock for helpful discussions. FWM received support from a PPARC Visiting Fellowship during this study.

Topical Editor G. Chanteur thanks two referees for their help in evalutating this paper.

\section{References}

Ables, S. T., Fraser, B. J. Waters, C. L., and Neudegg, D. A.: Monitoring cusp/cleft topology using Pc5 ULF waves, Geophys. Res. Lett., 25, 1507-1510, 1998.

Araki, T. and Nagano, H.: Geomagnetic response to sudden expansions of the magnetosphere, J. Geophys. Res., 93, 3983-3988, 1988.

Baker, K. B., Dudeney, J. R., Greenwald, R. A., Pinnock, M., Newell, P. T., Rodger, A. S., Mattin, N., and Meng, C.-I.: HF radar signatures of the cusp and low-latitude boundary layer, J. Geophys. Res., 100, 7671-7695, 1995.

Beamish, D., Hanson, H. W., and Webb, D. C.: Complex demodulation applied to Pi2 geomagnetic pulsations, Geophys. J. R. Astron. Soc., 58, 471-493, 1979.

Blagoveshchenskaya, N. F., Kornienko, V. A., Petlenko, A. V., Brekke, A., and Rietveld, M. T.: Geophysical phenomena during an ionospheric modification experiment at Troms $\emptyset$, Norway, Ann. Geophysicae, 16, 1212-1225, 1998.

Browne, S., Hargreaves, J. K., and Honary, B.: An imaging riometer for ionospheric studies, J. Elec. Comms. Eng., 7, 209-217, 1995.

Cahill, L., Greenwald, R. A., and Nielsen, E.: Auroral and rocket double-probe observations of the electric field across the Harang discontinuity, Geophys. Res. Lett., 5, 687-690, 1978.

Chaston, C. C., Hansen, H. J., Menk, F. W., Fraser, B. J., and Hu, Y. D.: Ground signatures of convecting reconnecting flux tubes, J. Geophys. Res., 98, 19 151-19 161, 1993.

Chisham, G. and Mann, I. R.: A Pc5 ULF wave with large azimuthal wavenumber observed within the morning sector plasmasphere by SAMNET, J. Geophys. Res., 104, 14 717-14 727, 1999.

Dettrick, D. L. and Rosenberg, T. J.: A phased-array radiowave imager for studies of cosmic noise absorption, Radio Sci., 25, 325-338, 1990.

Farrugia, C. J., Freeman, M. P., Cowley, S. W. H., Southwood, D. J., Lockwood, M., and Etemadi, A.: Pressure-driven magnetopause motions and attendant response on the ground, Planet. Space Sci., 37, 589-607, 1989.

Fejer, B. G. and Kelley, M. C.: Ionospheric irregularities, Rev. Geophys., 18, 401-454, 1980.

Greenwald, R. A., Baker, K. B., Hutchins, R. A., and Hanuise, C.: An HF phased-array radar for studying small-scale structure in the high-latitude ionosphere, Radio Sci., 20, 63, 1985.

Greenwald, R. A., Baker, K. B., Dudeney, J. R., Pinnock, M., Jones, T. B., Thomas, E. C., Villain, J.-P., Cerisier, J.-C., Senior, C., Hanuise, C., Hunsucker, R. D., Sofko, G., Koehler, J., Nielsen, E., Pellinan, R., Walker, A. D. M., Sato, N., and Yamag- 
ishi, H.: DARN/SuperDARN: a global view of the dynamics of high-altitude convection, Space Sci. Rev., 71, 761-796, 1995.

Hardy, D. A., Schmitt, L. K., Gussenhoven, M. S., Marshall, F. J., Yeh, H. C., Schumaker, T. L., Hube, A., and Pantazis, J.: Precipitating electron and ion detectors (SSJ/4) for the block 5D/flights 6-10 DMSP satellites: Calibration and data presentation, Rep. AFGL-TR-84-0317, Air Force Geophys. Lab., Hanscom Air Force Base, Mass., 1985.

Hasegawa, A., Tsui, K. H., and Assis, A. S.: A theory of long period magnetic pulsations, 3, Local field line oscillations, Geophys. Res. Lett., 10, 765-768, 1983.

Kivelson, M. G. and Southwood, D. J.: Hydromagnetic waves and the ionosphere, Geophys. Res. Lett., 15, 1271-1274, 1988.

Lemaire, J.: Impulsive penetration of filamentary plasma elements into the magnetosphere of the Earth and Jupiter, Planet. Space Sci., 25, 887-890, 1977.

Lepping, R. P., Acuna, M., Burlaga, L., Farrell, W., Slavin, J., Schatten, K., Mariani, F., Ness, N., Neubauer, F., Whang, Y. C., Byrnes, J., Kennon, R., Panetta, P., Scheifele, J., and Worley, E.: The WIND Magnetic Field Investigation, Space Sci. Rev., 71, 207-229, 1995.

Liu, A. T. Y. and Sibeck, D. G.: Dayside auroral activities and their implications for impulsive entry processes in the dayside magnetosphere, J. Atmos. Terr. Phys., 53, 219-229, 1991.

Lockwood, M., Sandholt, P. E., Cowley, S. W. H., and Oguti, T.: Interplanetary magnetic field control of dayside auroral activity and the transfer of momentum across the dayside magnetopause, Planet. Space Sci., 37, 1347-1365, 1989.

Lühr, H.: The IMAGE magnetometer network, STEP Int. Newsl., 4, 4-6, 1994.

Lühr, H., Aylward, A., Bucher, S. C., Pajunpää, A., Pajunpää, K., Holmbee, T., and Zalewski, S. M.: Westward moving dynamic substorm features observed with the IMAGE magnetometer network and other ground-based instruments, Ann. Geophysicae, 16, 425-440, 1998.

Mathie, R. A., Mann, I. R., Menk, F. W., and Orr, D.: Pc5 ULF pulsations associated with waveguide modes observed with the IMAGE magnetometer array, J. Geophys. Res., 104, 7025-7036, 1999a.

Mathie, R. A., Menk, F. W., Mann, I. R., and Orr, D.: Discrete field line resonances and the Alfvén continuum in the outer magnetosphere, Geophys. Res. Lett., 26, 659-662, 1999b.

Matthews, D. L., Ruohoniemi, J. M., Dudeney, J. R., Farrugia, C. F., Lanzerotti, L. J., and Friis-Christensen, E.: Conjugate cusp-region ULF pulsation responses to the solar wind event of May 23, 1989, J. Geophys. Res., 101, 7829-7841, 1996.

McWilliams, K. A., Yeoman, T. K., and Provan, G.: A statistical survey of dayside pulsed ionospheric flows as seen by the CUTLASS Finland HF radar, Ann. Geophysicae, 18, 445-453, 2000.

McWilliams, K. A., Yeoman, T. K., and Cowley, S. W. H.: Twodimensional electric field measurements in the ionospheric signature of a flux transfer event, Ann. Geophysicae, 18, 15841598,2001

Menk, F. W., Orr, D., Clilverd, M. A., Smith, A. J., Waters, C. L., and Fraser, B. J.: Monitoring spatial and temporal variations in the dayside plasmasphere using geomagnetic field line resonances, J. Geophys. Res., 104, 19955-19970, 1999.

Menk, F. W., Yeoman, T. K., Wright, D., and Lester, M.: Coordinated observations of forced and resonant field line observations at high-latitudes, ANARE Res. Rpts., 146, 383-404, 2001.

Milan, S. E., Jones, T. B., Robinson, T. R., Thomas, E. C., and Yeoman, T. K.: Interferometric evidence for the observation of ground backscatter originating behind the CUTLASS coherent HF radars, Ann. Geophysicae, 15, 29-39, 1997a.

Milan, S. E., Yeoman, T. K., and Lester, M.: Initial backscatter occurrence statistics from the CUTLASS HF radars, Ann. Geophysicae, 15, 703-718, 1997b.

Milan, S. E., Yeoman, T. K., and Lester, M.: The dayside auroral zone as a hard target for coherent HF radars, Geophys. Res.Lett., 25, 3717-3720, 1998.

Neudegg, D. A., Yeoman, T. K., Cowley, S. W. H., Provan, G., Haerendel, G., Baumjohann, W., Auster, U., Fornacon, K.-H., Georgescu, E., and Owen, C. J.: A flux transfer event observed at the magnetopause by the Equator-S spacecraft and in the ionosphere by the CUTLASS HF radar, Ann. Geophysicae, 17, 707$711,1999$.

Newell, P. T. and Meng, C.-I.: The cusp and cleft/boundary layer: Low-altitude identifications and statistical local time variation, J. Geophys. Res., 93, 14 549-14 556, 1988.

Newell, P. T., Meng, C.-I., Sibeck, D. G., and Lepping, R.: Some low altitude cusp dependencies on the interplanetary magnetic field, J. Geophys. Res., 94, 8921-8927, 1989.

Newell, P. T., Wing, S., Meng, C.-I., and Sigilleto, V.: The auroral oval position, structure, and intensity of precipitation from 1984 onwards: An automated online data base, J. Geophys. Res., 96, 5877-5882, 1991

Newell, P. T. and Meng, C.-I.: Mapping the dayside ionosphere to the magnetosphere according to particle precipitation characteristics, Geophys. Res. Lett., 19, 609-612, 1992.

Øieroset, M., Sandholt, P. E., Luhr, H., Denig, W. F., and Moretto, T.: Auroral and geomagnetic events at cusp/mantle latitudes in the prenoon sector during positive IMF By conditions: Signatures of pulsed magnetopause reconnection, J. Geophys. Res., 102, 7191-7205, 1997

Ogilvie, K. W., Chorney, D. J., Fitzenreiter, R. J., Hunsaker, F., Keller, J., Lobell, J., Miller, G., Scudder, J. D., Sittler Jr., E. C., Torbert, R. B., Bodet, D., Needell, G., Lazarus, A. J., Steinberg, J. T., Tappan, J. H., Mavretic, A., and Gergin, E.: SWE, a comprehensive plasma instrument for the Wind spacecraft, Space Sci. Rev, 71, 55-77, 1995.

Parkhomov, V. A., Mishin, V. V., and Borovik, L. V.: Long-period goemagnetic pulsations caused by the solar wind negative pressure impulse on 22 March 1979 (CDAW-6), Ann. Geophysicae, 16, 134-139, 1998

Pinnock, M., Rodger, A. S., Dudeney, J. R., Greenwald, R. A., Baker, K. B., and Ruohoniemi, J. M.: An ionospheric signature of possible enhanced magnetic field merging on the dayside magnetopause, J. Atmos. Terr. Phys., 53, 201-212, 1991.

Pinnock, M., Rodger, A. S., Dudeney, J. R., Baker, K. B., Newell, P. T., Greenwald, R. A., and Greenspan, M. E.: Observations of an enhanced convection channel in the cusp ionosphere, J. Geophys. Res., 98, 3767-3776, 1993.

Pinnock, M., Rodger, A. S., Dudeney, J. R., Rich, F., and Baker, K.: High spatial and temporal resolution observations of the ionospheric cusps, Ann. Geophysicae, 13, 919-925, 1995.

Poole, A. W. V., Sutcliffe, P. R., and Walker, A. D. M.: The relationship between ULF geomagnetic pulsations and ionospheric Doppler oscillations: derivation of a model, J. Geophys. Res., 93, 14 656-14 664, 1988.

Potemra, T. A., Lühr, H., Zanetti, L. J., Takahashi, K., Erlandson, R. E., Marklund, G. T., Block, L. P., Blomberg, L. G., and Lepping, R. P.: Multisatellite and ground-based observations of transient ULF waves, J. Geophys. Res., 94, 2543-2554, 1989.

Poulter, E. M. and Allan, W.: Transient ULF pulsation decay rates 
observed by ground based magnetometers: the contribution of spatial integration, Planet. Space Sci., 33, 607-616, 1985.

Prikryl, P., Greenwald, R. A., Sofko, G. J., Villain, J. P., Ziesolleck, C.W.S., and Friis-Christensen, E.: Solar-wind-driven pulsed magnetic reconnection at the dayside magnetopause, Pc5 compressional oscillations, and field line resonances, J. Geophys. Res., 103, 17 307-17 322, 1998.

Provan, G., Yeoman, T. K., and Milan, S. E.: CUTLASS Finland radar observations of the ionospheric signatures of flux transfer events and the resulting plasma flows, Ann. Geophysicae, 16, 1411-1422, 1998.

Provan, G. and Yeoman, T. K.: Statistical observations of the MLT, latitude and size of pulsed ionospheric flows with the CUTLASS Finland radar, Ann. Geophysicae, 17, 855-867, 1999.

$\mathrm{Pu}, \mathrm{Z}$.-Y. and Kivelson, M. G.: Kelvin-Helmholtz instability at the magnetopause: solutions for compressible plasmas, J. Geophys. Res., 88, 841-852, 1983.

Risbeth, H. and Garriott, O. K.: Relationship between simultaneous geomagnetic and ionospheric oscillations, Radio Sci., 68D, 339343, 1964.

Rodger, A. and Pinnock, M.: The ionospheric response to flux transfer events: the first few minutes, Ann. Geophysicae, 15, 685691, 1997.

Russell, C. T. and Elphic, R. C.: ISEE observations of flux transfer events at the dayside magnetopause, Geophys. Res. Lett., 6, 3336, 1979.

Saunders, M. A., Russell, C. T. , and Sckopke, N.: Flux transfer events: scale size and interior structure, Geophys. Res. Lett., 11, 131-134, 1984.

Sedgemore, K. J. F., Williams, P. J. S., Jones, G. O. L. , and Wright, J. W.: A comparison of EISCAT and Dynasonde measurements of the auroral ionosphere, Ann. Geophysicae, 14, 1403-1412, 1996.

Sibeck, D. G.: A model for the transient magnetospheric response to sudden solar wind dynamic pressure perturbations, J. Geophys. Res., 95, 3755-3771, 1990

Southwood, D. J.: The ionospheric signature of flux transfer events, J. Geophys. Res., 92, 3207-3213, 1987.

Sutcliffe, P. R. and Poole, A. W. V.: Ionospheric Doppler and electron velocities in the presence of ULF waves, J. Geophys. Res., 94, 13 505-13 514, 1989.

Takahashi, K., Kistler, L. M., Potemra, T. A., McEntire, R. W., and Zanetti, L. J.: Magnetospheric ULF waves observed during the major magnetospheric compression of November 1, 1984, J. Geophys. Res., 93, 14369-14382, 1988.

Tsunoda, R. T.: High-latitude F-region irregularities: a review and synthesis, Rev. Geophys., 26, 719-760, 1988.

Villain, J. P., Caudal, G., and Hanuise, C.: A Safari-Eiscat comparison between the velocity of $\mathrm{F}$ region small-scale irregularities and the ion drift, J. Geophys. Res., 90, 8433-8443, 1985.

Walker, A. D. M., Greenwald, R. A., Stuart, W. F., and Green, C. A.: STARE auroral radar observations of Pc5 geomagnetic pulsations, J. Geophys. Res., 84, 3373-3388, 1979.

Warnecke, J., Lühr, H., and Takahashi, K.: Observational features of field line resonances excited by solar wind pressure variations on 4 September 1984, Planet. Space Sci., 38, 1517-1531, 1990.

Waters, C. L., Samson, J. C., and Donovan, E. F.: The temporal variation of the frequency of high-latitude field line resonances, J. Geophys. Res., 100, 7987-7996, 1995.

Waters, C. L., Sciffer, M., Dunlop, I. S., and Menk, F. W.: HF Doppler oscillations due to mixed ULF wave modes, ANARE Res. Rpts., 146, 369-382, 2001.

Wild, J. A., Cowley, S. W. H., Davies, J. A., Kahn, H., Lester, M., Milan, S. E.,Provan, G. , Yeoman, T. K., Balogh, A., Dunlop, M. W., Fornaçon, K.-H., and Georgescu, E.: First simultaneous observations of flux transfer events at the high-latitude magnetopause by the Cluster spacecraft and pulsed radar signatures in the conjugate ionosphere by the CUTLASS and EISCAT radars, Ann. Geophysicae, 19, 1491-1508, 2001.

Wright, D. M., Yeoman, T. K., and Chapman, P. J.: High-latitude HF Doppler observations of ULF waves. 1. Waves with large spatial scale sizes, Ann. Geophysicae, 15, 1548-1556, 1997.

Wright, D. M., Yeoman, T. K., and Davies, J. A.: A comparison of EISCAT and HF Doppler observations of a ULF wave event, Ann. Geophysicae, 16, 1190-1199, 1998.

Yeoman, T. K. and Lester, M. E.: Characteristics of MHD waves associated with storm sudden commencements observed by SABRE and ground magnetometers, Planet. Space Sci., 38, 603616, 1990.

Yeoman, T. K., Milling, D. K., and Orr, D.: Pi2 polarization patterns on the U.K. Sub-Auroral Magnetometer Network (SAMNET), Planet. Space Sci., 38, 589-602, 1990a.

Yeoman, T. K., Lester, M., Orr, D., and Lühr, H.: Ionospheric boundary conditions of hydromagnetic waves: the dependence on azimuthal wave number and a case study, Planet. Space Sci., 38, 1315-1325, 1990b.

Yeoman, T. K., Wright, D. M., Robinson, T. R., Davies, J. A., and Rietveld, M.: High spatial and temporal resolution observations of an impulse-driven field line resonance in radar backscatter data artificially generated with the Troms $\varnothing$ heater, Ann. Geophysicae, 16, 634-644, 1997. 